NBER WORKING PAPER SERIES

\title{
OPTIMAL INFLATION STABILIZATION IN A MEDIUM-SCALE MACROECONOMIC MODEL
}

\author{
Stephanie Schmitt-Grohé \\ Martin Uribe \\ Working Paper 11854 \\ http://www.nber.org/papers/w11854
NATIONAL BUREAU OF ECONOMIC RESEARCH
1050 Massachusetts Avenue
Cambridge, MA 02138
December 2005

This paper was prepared for the Central Bank of Chile Annual Conference to be held on October 20-21, 2005 in Santiago, Chile. We thank Jan Marc Berk and Juan Pablo Medina for comments and Anna Kozlovskaya for research assistance. The views expressed herein are those of the author(s) and do not necessarily reflect the views of the National Bureau of Economic Research.

(C2005 by Stephanie Schmitt-Grohé and Martin Uribe. All rights reserved. Short sections of text, not to exceed two paragraphs, may be quoted without explicit permission provided that full credit, including (C) notice, is given to the source. 
Optimal Inflation Stabilization in a Medium-Scale Macroeconomic Model

Stephanie Schmitt-Grohé and Martin Uribe

NBER Working Paper No. 11854

December 2005, Revised July 2006

JEL No. E52, E61, E63

\begin{abstract}
$\underline{\text { ABSTRACT }}$
This paper characterizes Ramsey-optimal monetary policy in a medium-scale macroeconomic model that has been estimated to fit well postwar U.S.I business cycles. We find that mild deflation is Ramsey optimal in the long run. However, the optimal inflation rate appears to be highly sensitive to the assumed degree of price stickiness. Within the window of available estimates of price stickiness (between 2 and 5 quarters) the optimal rate of inflation ranges from -4.2 percent per year (close to the Friedman rule) to -0.4 percent per year (close to price stability). This sensitivity disappears when one assumes that lump-sum taxes are unavailable and fiscal instruments take the form of distortionary income taxes. In this case, mild deflation emerges as a robust Ramsey prediction. In light of the finding that the Ramsey-optimal inflation rate is negative, it is puzzling that most inflation-targeting countries pursue positive inflation goals. We show that the zero bound on the nominal interest rate, which is often cited as a rationale for setting positive inflation targets, is of no quantitative relevance in the present model. Finally, the paper characterizes operational interest-rate feedback rules that best implement Ramsey-optimal stabilization policy. We find that the optimal interest-rate rule is active in price and wage inflation, mute in output growth, and moderately inertial. This rule achieves virtually the same level of welfare as the Ramsey optimal policy.
\end{abstract}

Stefanie Schmitt-Grohé

Department of Economics

Duke University

P.O. Box 9009

Durham, NC 27708

and NBER

grohe@duke.edu

Martin Uribe

Department of Economics

Duke University

Durham, NC 27708-0097

and NBER

uribe@duke.edu 


\section{Contents}

1 Introduction $\quad 2$

2 The Model $\quad 5$

2.1 Households . . . . . . . . . . . . . . . . . . . . . . . 5

2.2 Firms . . . . . . . . . . . . . . . . . . . . . 13

2.3 The Government . . . . . . . . . . . . . . . . . . 17

2.4 Aggregation . . . . . . . . . . . . . . . . . . . . . . . 18

2.4.1 Market Clearing in the Final Goods Market . . . . . . . . . . . . . . 18

2.4.2 Market Clearing in the Labor Market . . . . . . . . . . . . . . . . . . 20

2.5 Functional Forms . . . . . . . . . . . . . . . . . . . . . 22

2.6 Inducing Stationarity . . . . . . . . . . . . . . . . 23

2.7 Competitive Equilibrium . . . . . . . . . . . . . . . . . . . 23

2.8 Ramsey Equilibrium . . . . . . . . . . . . . . . . . . . . . . 23

3 Calibration $\quad 24$

4 The Ramsey Steady State $\quad 26$

4.1 Price Stickiness and the Optimal Inflation Rate . . . . . . . . . . . . . 26

4.2 Fiscal Policy and the Optimal Inflation Rate . . . . . . . . . . . . . . . . . 29

4.3 Price Indexation and the Optimal Inflation Rate . . . . . . . . . . . . . . . 32

4.4 Money Demand and the Optimal Inflation Rate . . . . . . . . . . . . . . . 33

4.5 Implications for Inflation Targeting . . . . . . . . . . . . . . . . . . . . . 34

5 Ramsey Dynamics $\quad 35$

5.1 Is the Zero Bound an Impediment to Optimal Policy? . . . . . . . . . . . . . 35

5.2 Optimality of Inflation Stability . . . . . . . . . . . . . . . . 37

5.3 Ramsey Optimal Impulse Responses and Variance Decomposition . . . . . . 37

6 Optimal Operational Interest-Rate Rules 43

6.1 The Optimal Operational Rule . . . . . . . . . . . . . . . . . . 44

6.2 Interest-Rate Rules and Equilibrium Determinacy . . . . . . . . . . . . . . . 47

7 Discussion and Conclusion $\quad 52$ 


\section{Introduction}

Two fundamental but separate questions in the theory of monetary stabilization policy are what is the optimal monetary policy and how can the central bank implement it. Both questions have been extensively studied in the existing related literature, but always in the context of simple theoretical structures, which by design are limited in their ability to account for actual observed business-cycle fluctuations. The goal of this paper is to characterize optimal monetary policy and its implementation using a medium-scale, empirically plausible model of the U.S. business cycle.

The model we consider is the one developed in Altig et al. (2005). This model has been estimated econometrically and shown to account fairly well for business-cycle fluctuations in the postwar United States. The theoretical framework emphasizes the importance of combining nominal as well as real rigidities in explaining the propagation of macroeconomic shocks. Specifically, the model features four nominal frictions, sticky prices, sticky wages, a transactional demand for money by households, and a cash-in-advance constraint on the wage bill of firms, and four sources of real rigidities, investment adjustment costs, variable capacity utilization, habit formation, and imperfect competition in product and factor markets. Aggregate fluctuations are driven by three shocks: a permanent neutral technology shock, a permanent investment-specific technology shock, and temporary variations in government spending. Altig et al. (2005) and Christiano, Eichenbaum, and Evans (2005) argue that the model economy for which we seek to design optimal monetary policy can indeed explain the observed responses of inflation, real wages, nominal interest rates, money growth, output, investment, consumption, labor productivity, and real profits to neutral and investment-specific productivity shocks and monetary shocks in the postwar United States.

In our characterization of optimal monetary policy, we depart from the widespread practice in the neo-Keynesian literature on optimal monetary policy of limiting attention to models in which the nonstochastic steady state is undistorted. Most often, this approach involves assuming the existence of a battery of subsidies to production and employment aimed at eliminating the long-run distortions originating from monopolistic competition in factor and product markets. The efficiency of the deterministic steady-state allocation is assumed for purely computational reasons. For it allows the use of first-order approximation techniques to evaluate welfare accurately up to second order (see Rotemberg and Woodford, 1997). This practice has two potential shortcomings. First, the instruments necessary to bring about an undistorted steady state (e.g., labor and output subsidies financed by lumpsum taxation) are empirically uncompelling. Second, it is ex ante not clear whether a policy that is optimal for an economy with an efficient steady state will also be so for an economy 
where the instruments necessary to engineer the nondistorted steady state are unavailable. For these reasons, we refrain from making the efficient-steady-state assumption and instead work with a model whose steady state is distorted.

Departing from a model whose steady state is Pareto efficient has a number of important ramifications. One is that to obtain a second-order accurate measure of welfare it no longer suffices to approximate the equilibrium of the model up to first order. We solve the equilibrium of the model up to second order using the methodology and computer code developed in Schmitt-Grohé and Uribe (2004c) for second-order accurate approximations to policy functions of dynamic, stochastic models. One advantage of this numerical strategy is that because it is based on perturbation arguments, it is particularly well suited to handle economies with a large number of state variables like the one studied in this paper.

We address the first question posed above, namely, what business-cycle fluctuations should look like under optimal monetary policy by characterizing the Ramsey equilibrium associated with our model. The central policy problem faced by the monetary authority is, on the one hand, the need to stabilize prices so as to minimize price dispersion stemming from nominal rigidities and, on the other hand, the need to minimize and stabilize the opportunity cost of holding money to avoid transactional frictions. The task of characterizing Ramsey-optimal policy is challenging because the model is large and highly distorted. A methodological contribution of the research project to which this paper belongs is the development of computational procedures to derive and characterize the Ramsey equilibrium for a general class of dynamic rational expectations models. ${ }^{1}$

We find that the policy tradeoff faced by the Ramsey planner is resolved in favor of price stability. In effect, the Ramsey optimal inflation rate is -0.4 percent per annum, with a standard deviation of only 0.1 percentage points. The optimality of near-zero inflation, however, is highly sensitive to the assumed degree of price stickiness. Available estimates of the degree of price stickiness vary between 2 and 5 quarters. Within this range, the optimal rate of inflation increases from a deflation of about 4 percent per year when prices are reoptimized every two quarters to a mild deflation of less than half a percent when prices are reoptimized every five quarters. So, depending on what available estimate of price rigidity one chooses to pick, the Ramsey-optimal policy can range from close to the Friedman rule, to close to price stability.

Quite independently of the precise degree of price stickiness, the optimal inflation target is below zero. In light of this robust result, it is puzzling that all countries that self-classify as inflation targeters set inflation targets that are positive. In effect, in the developed world

\footnotetext{
${ }^{1}$ Matlab code to replicate the quantitative results reported in this paper is available on the authors' websites.
} 
inflation targets range between 2 and 4 percent per year. Somewhat higher targets are observed across developing countries. An argument often raised in defense of positive inflation targets is that negative inflation targets imply nominal interest rates that are dangerously close to the zero lower bound on nominal interest rates and hence may impair the central bank's ability to conduct stabilization policy. We find, however, that this argument is of no relevance in the context of the medium-scale estimated model within which we conduct policy evaluation. The reason is that under the optimal policy regime, the mean of the nominal interest rate is about 4.5 percent per year with a standard deviation of only 0.4 percent. This means that for the zero lower bound to pose an obstacle to monetary policy, the economy must suffer from an adverse shock that forces the interest rate to be more than 10 standard deviations below target. The likelihood of such an event is practically nil.

We address the question of implementation of optimal monetary policy by characterizing optimal, simple, and implementable interest-rate feedback rules. We restrict attention to what we call operational interest rate rules. By an operational interest-rate rule we mean an interest-rate rule that satisfies three requirements. First, it prescribes that the nominal interest rate is set as a function of a few readily observable macroeconomic variables. In the tradition of Taylor (1993), we focus on rules whereby the nominal interest rate depends on measures of inflation, aggregate activity, and possibly its own lag. Second, the operational rule must induce an equilibrium satisfying the zero lower bound on nominal interest rates. And third, operational rules must render the rational expectations equilibrium unique. This last restriction closes the door to expectations driven aggregate fluctuations.

Our numerical findings suggest that in the model economy we study, the optimal operational interest-rate rule responds aggressively to deviations of price and wage inflation from target. The price-inflation coefficient is about 5 and the wage-inflation coefficient is about 2 . In addition, the optimal interest-rate rule prescribes a mute response to deviations of output growth from target. In this sense, the implementation of optimal policy calls for following a regime of inflation targeting. The parameters of the optimized rule are robust to using a conditional or unconditional measure of welfare.

Remarkably, the optimal operational interest-rate rule delivers a welfare level that is virtually identical to the one obtained under the Ramsey-optimal policy. Specifically, the welfare cost associated with living in an economy where the monetary authority follows the optimal operational rule as opposed to living in the Ramsey economy is only 0.23 dollars per year per person (or 0.001 percent of 2006 annual per capita consumption).

The remainder of the paper is organized in five sections. Section 2 presents the theoretical economy and derives nonlinear recursive representations for the price and wage Phillips curves as well as for the state variables summarizing the degree of wage and price disper- 
sion. Section 3 describes the calibration of the model and discusses the solution method. Section 4 characterizes the steady state of the Ramsey equilibrium. Section 5 studies the dynamics induced by the Ramsey monetary policy. Section 6 computes the optimal operational interest-rate rule. Section 7 provides concluding remarks.

\section{The Model}

The skeleton of the model economy that we use for policy evaluation is a standard neoclassical growth model driven by neutral and investment-specific productivity shocks and government spending shocks. In addition the economy features four sources of nominal frictions and five real rigidities. The nominal frictions include price and wage stickiness à la Calvo (1983) and Yun (1996) with indexation to past inflation, and money demands by households and firms. The real rigidities originate from internal habit formation in consumption, monopolistic competition in factor and product markets, investment adjustment costs, and variable costs of adjusting capacity utilization.

To perform monetary policy evaluation, we are forced to approximate the equilibrium conditions of the economy to an order higher than linear. To this end, we derive the exact nonlinear recursive representation of the complete set of equilibrium conditions. Of particular interest is the recursive nonlinear representation of the equilibrium Phillips curves for prices and wages. These representations depart from most of the existing literature, which restricts attention to linear approximations to these functions. Another byproduct of deriving the exact nonlinear set of equilibrium conditions is the emergence of two state variables measuring the degree of price and wage dispersion in the economy induced by the sluggishness in the adjustment of nominal product and factor prices. We present a recursive representation of these state variables and track their dynamic behavior.

\subsection{Households}

The economy is assumed to be populated by a large representative family with a continuum of members. Consumption and hours worked are identical across family members. The household's preferences are defined over per capita consumption, $c_{t}$, and per capita labor effort, $h_{t}$, and are described by the utility function

$$
E_{0} \sum_{t=0}^{\infty} \beta^{t} U\left(c_{t}-b c_{t-1}, h_{t}\right)
$$


where $E_{t}$ denotes the mathematical expectations operator conditional on information available at time $t, \beta \in(0,1)$ represents a subjective discount factor, and $U$ is a period utility index assumed to be strictly increasing in its first argument, strictly decreasing in its second argument, and strictly concave. Preferences display internal habit formation, measured by the parameter $b \in[0,1)$. The consumption good is assumed to be a composite made of a continuum of differentiated goods $c_{i t}$ indexed by $i \in[0,1]$ via the aggregator

$$
c_{t}=\left[\int_{0}^{1} c_{i t}^{1-1 / \eta} d i\right]^{1 /(1-1 / \eta)}
$$

where the parameter $\eta>1$ denotes the intratemporal elasticity of substitution across different varieties of consumption goods.

For any given level of consumption of the composite good, purchases of each individual variety of goods $i \in[0,1]$ in period $t$ must solve the dual problem of minimizing total expenditure, $\int_{0}^{1} P_{i t} c_{i t} d i$, subject to the aggregation constraint (2), where $P_{i t}$ denotes the nominal price of a good of variety $i$ at time $t$. The demand for goods of variety $i$ is then given by

$$
c_{i t}=\left(\frac{P_{i t}}{P_{t}}\right)^{-\eta} c_{t},
$$

where $P_{t}$ is a nominal price index defined as

$$
P_{t} \equiv\left[\int_{0}^{1} P_{i t}^{1-\eta} d i\right]^{\frac{1}{1-\eta}}
$$

This price index has the property that the minimum cost of a bundle of intermediate goods yielding $c_{t}$ units of the composite good is given by $P_{t} c_{t}$.

Labor decisions are made by a central authority within the household, a union, which supplies labor monopolistically to a continuum of labor markets of measure 1 indexed by $j \in[0,1]$. In each labor market $j$, the union faces a demand for labor given by $\left(W_{t}^{j} / W_{t}\right)^{-\tilde{\eta}} h_{t}^{d}$. Here $W_{t}^{j}$ denotes the nominal wage charged by the union in labor market $j$ at time $t, W_{t}$ is an index of nominal wages prevailing in the economy, and $h_{t}^{d}$ is a measure of aggregate labor demand by firms. We postpone a formal derivation of this labor demand function until we consider the firm's problem. In each particular labor market, the union takes $W_{t}$ and $h_{t}^{d}$ as exogenous. $^{2}$ Given the wage it charges in each labor market $j \in[0,1]$, the union is assumed

\footnotetext{
${ }^{2}$ The case in which the union takes aggregate labor variables as endogenous can be interpreted as an environment with highly centralized labor unions. Higher-level labor organizations play an important role in some European and Latin American countries, but are less prominent in the United States.
} 
to supply enough labor, $h_{t}^{j}$, to satisfy demand. That is,

$$
h_{t}^{j}=\left(\frac{w_{t}^{j}}{w_{t}}\right)^{-\tilde{\eta}} h_{t}^{d}
$$

where $w_{t}^{j} \equiv W_{t}^{j} / P_{t}$ and $w_{t} \equiv W_{t} / P_{t}$. In addition, the total number of hours allocated to the different labor markets must satisfy the resource constraint

$$
h_{t}=\int_{0}^{1} h_{t}^{j} d j
$$

Combining this restriction with equation (5), we obtain

$$
h_{t}=h_{t}^{d} \int_{0}^{1}\left(\frac{w_{t}^{j}}{w_{t}}\right)^{-\tilde{\eta}} d j .
$$

Our setup of imperfectly competitive labor markets departs from most existing expositions of models with nominal wage inertia (e.g., Erceg, et al., 2000). For in these models, it is assumed that each household supplies a differentiated type of labor input. This assumption introduces equilibrium heterogeneity across households in the number of hours worked. To avoid this heterogeneity from spilling over into consumption heterogeneity, it is typically assumed that preferences are separable in consumption and hours and that financial markets exist that allow agents to fully insure against employment risk. Our formulation has the advantage that it avoids the need to assume both separability of preferences in leisure and consumption and the existence of such insurance markets. As we will explain later in more detail, our specification gives rise to a wage-inflation Phillips curve with a larger coefficient on the wage-markup gap than the model with employment heterogeneity across households.

The household is assumed to own physical capital, $k_{t}$, which accumulates according to the following law of motion

$$
k_{t+1}=(1-\delta) k_{t}+i_{t}\left[1-\mathcal{S}\left(\frac{i_{t}}{i_{t-1}}\right)\right]
$$

where $i_{t}$ denotes gross investment and $\delta$ is a parameter denoting the rate of depreciation of physical capital. The function $\mathcal{S}$ introduces investment adjustment costs. It is assumed that in the steady state, the function $\mathcal{S}$ satisfies $\mathcal{S}=\mathcal{S}^{\prime}=0$ and $\mathcal{S}^{\prime \prime}>0$. These assumptions imply the absence of adjustment costs up to first-order in the vicinity of the deterministic steady state.

As in Fisher (2005) and Altig et al. (2005), it is assumed that investment is subject 
to permanent investment-specific technology shocks. Fisher argues that this type of shock is needed to explain the observed secular decline in the relative price of investment goods in terms of consumption goods. More importantly, Fisher shows that investment-specific technology shocks account for about 50 percent of aggregate fluctuations at business-cycle frequencies in the postwar U.S. economy. (As we will discuss below, Altig et al., 2005, find smaller numbers in the context of the model studied in our paper.)

We assume that investment goods are produced from consumption goods by means of a linear technology whereby $1 / \Upsilon_{t}$ units of consumption goods yield one unit of investment goods, where $\Upsilon_{t}$ denotes an exogenous, permanent technology shock in period $t$. The growth rate of $\Upsilon_{t}$ is assumed to follow an $\operatorname{AR}(1)$ process of the form:

$$
\hat{\mu}_{\Upsilon, t}=\rho_{\mu_{\Upsilon}} \hat{\mu}_{\Upsilon, t-1}+\epsilon_{\mu_{\Upsilon}, t}
$$

where $\hat{\mu}_{\Upsilon, t} \equiv \ln \left(\mu_{\Upsilon, t} / \mu_{\Upsilon}\right)$ denotes the percentage deviation of the gross growth rate of investment specific technological change and $\mu_{\Upsilon}$ denotes the steady-state growth rate of $\Upsilon_{t}$.

Owners of physical capital can control the intensity at which this factor is utilized. Formally, we let $u_{t}$ measure capacity utilization in period $t$. We assume that using the stock of capital with intensity $u_{t}$ entails a cost of $\Upsilon_{t}^{-1} a\left(u_{t}\right) k_{t}$ units of the composite final good. The function $a$ is assumed to satisfy $a(1)=0$, and $a^{\prime}(1), a^{\prime \prime}(1)>0$. Both the specification of capital adjustment costs and capacity utilization costs are somewhat peculiar. More standard formulations assume that adjustment costs depend on the level of investment rather than on its growth rate, as is assumed here. Also, costs of capacity utilization typically take the form of a higher rate of depreciation of physical capital. The modeling choice here is guided by the need to fit the response of investment and capacity utilization to a monetary shock in the U.S. economy. For further discussion of this issue, see Christiano, Eichenbaum, and Evans (2005) and Altig et al. (2005).

Households rent the capital stock to firms at the real rental rate $r_{t}^{k}$ per unit of capital. Total income stemming from the rental of capital is given by $r_{t}^{k} u_{t} k_{t}$. The investment good is assumed to be a composite good made with the aggregator function shown in equation (2). Thus, the demand for each intermediate good $i \in[0,1]$ for investment purposes, $i_{i t}$, is given by $i_{i t}=\Upsilon_{t}^{-1} i_{t}\left(P_{i t} / P_{t}\right)^{-\eta}$.

As in our earlier related work (Schmitt-Grohé and Uribe, 2004a,b), we motivate a demand for money by households by assuming that purchases of consumption goods are subject to a proportional transaction cost that is increasing in consumption-based money velocity. 
Formally, the purchase of each unit of consumption entails a cost given by $\ell\left(v_{t}\right)$. Here,

$$
v_{t} \equiv \frac{c_{t}}{m_{t}^{h}}
$$

is the ratio of consumption to real money balances held by the household, which we denote by $m_{t}^{h}$. The transaction cost function $\ell$ satisfies the following assumptions: (a) $\ell(v)$ is nonnegative and twice continuously differentiable; (b) There exists a level of velocity $\underline{v}>0$, to which we refer as the satiation level of money, such that $\ell(\underline{v})=\ell^{\prime}(\underline{v})=0$; (c) $(v-\underline{v}) \ell^{\prime}(v)>0$ for $v \neq \underline{v}$; and (d) $2 \ell^{\prime}(v)+v \ell^{\prime \prime}(v)>0$ for all $v \geq \underline{v}$. Assumption (a) implies that the transaction process does not generate resources. Assumption (b) ensures that the Friedman rule, i.e., a zero nominal interest rate, need not be associated with an infinite demand for money. It also implies that both the transaction cost and the associated distortions in the intra and intertemporal allocation of consumption and leisure vanish when the nominal interest rate is zero. Assumption (c) guarantees that in equilibrium money velocity is always greater than or equal to the satiation level $\underline{v}$. As will become clear shortly, assumption (d) ensures that the demand for money is decreasing in the nominal interest rate. Assumption (d) is weaker than the more common assumption of strict convexity of the transaction cost function.

Households are assumed to have access to a complete set of nominal state-contingent assets. Specifically, each period $t \geq 0$, consumers can purchase any desired state-contingent nominal payment $X_{t+1}^{h}$ in period $t+1$ at the dollar cost $E_{t} r_{t, t+1} X_{t+1}^{h}$. The variable $r_{t, t+1}$ denotes a stochastic nominal discount factor between periods $t$ and $t+1$. Households pay real lump-sum taxes in the amount $\tau_{t}$ per period. The household's period-by-period budget constraint is given by:

$$
\begin{aligned}
E_{t} r_{t, t+1} x_{t+1}^{h}+c_{t}\left[1+\ell\left(v_{t}\right)\right]+\Upsilon_{t}^{-1}\left[i_{t}+a\left(u_{t}\right) k_{t}\right]+m_{t}^{h}+\tau_{t} & =\frac{x_{t}^{h}+m_{t-1}^{h}}{\pi_{t}}+r_{t}^{k} u_{t} k_{t} \\
& +\int_{0}^{1} w_{t}^{j}\left(\frac{w_{t}^{j}}{w_{t}}\right)^{-\tilde{\eta}} h_{t}^{d} d j+\phi_{t} .
\end{aligned}
$$

The variable $x_{t}^{h} / \pi_{t} \equiv X_{t}^{h} / P_{t}$ denotes the real payoff in period $t$ of nominal state-contingent assets purchased in period $t-1$. The variable $\phi_{t}$ denotes dividends received from the ownership of firms and $\pi_{t} \equiv P_{t} / P_{t-1}$ denotes the gross rate of consumer-price inflation.

We introduce wage stickiness in the model by assuming that each period the household (or unions) cannot set the nominal wage optimally in a fraction $\tilde{\alpha} \in[0,1)$ of randomly chosen labor markets. In these markets, the wage rate is indexed to average real wage growth and 
to the previous period's consumer-price inflation according to the rule

$$
W_{t}^{j}=W_{t-1}^{j}\left(\mu_{z^{*}} \pi_{t-1}\right)^{\tilde{\chi}}
$$

where $\tilde{\chi} \in[0,1]$ is a parameter measuring the degree of wage indexation. When $\tilde{\chi}$ equals 0 , there is no wage indexation. When $\tilde{\chi}$ equals 1 , there is full wage indexation to long-run real wage growth and to past consumer price inflation.

The household chooses processes for $c_{t}, h_{t}, x_{t+1}^{h}, w_{t}^{j}, k_{t+1}, i_{t}, u_{t}$, and $m_{t}^{h}$ so as to maximize the utility function (1) subject to (6)-(9), the wage stickiness friction, and a no-Ponzi-game constraint, taking as given the processes $w_{t}, r_{t}^{k}, h_{t}^{d}, r_{t, t+1}, \pi_{t}, \phi_{t}$, and $\tau_{t}$ and the initial conditions $x_{0}^{h}, k_{0}$, and $m_{-1}^{h}$. The household's optimal plan must satisfy constraints (6)-(9). In addition, letting $\beta^{t} \lambda_{t} w_{t} \tilde{\mu}_{t}, \beta^{t} \lambda_{t} q_{t}$, and $\beta^{t} \lambda_{t}$ denote Lagrange multipliers associated with constraints (6), (7), and (9), respectively, the Lagrangian associated with the household's optimization problem is

$$
\begin{aligned}
\mathcal{L}= & E_{0} \sum_{t=0}^{\infty} \beta^{t}\left\{U\left(c_{t}-b c_{t-1}, h_{t}\right)\right. \\
& +\lambda_{t}\left[h_{t}^{d} \int_{0}^{1} w_{t}^{i}\left(\frac{w_{t}^{i}}{w_{t}}\right)^{-\tilde{\eta}} d i+r_{t}^{k} u_{t} k_{t}+\phi_{t}-\tau_{t}\right. \\
& \left.-c_{t}\left[1+\ell\left(\frac{c_{t}}{m_{t}^{h}}\right)\right]-\Upsilon_{t}^{-1}\left[i_{t}+a\left(u_{t}\right) k_{t}\right]-r_{t, t+1} x_{t+1}^{h}-m_{t}^{h}+\frac{m_{t-1}^{h}+x_{t}^{h}}{\pi_{t}}\right] \\
& +\frac{\lambda_{t} w_{t}}{\tilde{\mu}_{t}}\left[h_{t}-h_{t}^{d} \int_{0}^{1}\left(\frac{w_{t}^{i}}{w_{t}}\right)^{-\tilde{\eta}} d i\right] \\
& \left.+\lambda_{t} q_{t}\left[(1-\delta) k_{t}+i_{t}\left[1-\mathcal{S}\left(\frac{i_{t}}{i_{t-1}}\right)\right]-k_{t+1}\right]\right\} .
\end{aligned}
$$

The first-order conditions with respect to $c_{t}, x_{t+1}^{h}, h_{t}, k_{t+1}, i_{t}, m_{t}^{h}, u_{t}$, and $w_{t}^{i}$, in that order, are given by

$$
\begin{gathered}
U_{c}\left(c_{t}-b c_{t-1}, h_{t}\right)-b \beta E_{t} U_{c}\left(c_{t+1}-b c_{t}, h_{t+1}\right)=\lambda_{t}\left[1+\ell\left(v_{t}\right)+v_{t} \ell^{\prime}\left(v_{t}\right)\right], \\
\lambda_{t} r_{t, t+1}=\beta \lambda_{t+1} \frac{P_{t}}{P_{t+1}} \\
-U_{h}\left(c_{t}-b c_{t-1}, h_{t}\right)=\frac{\lambda_{t} w_{t}}{\tilde{\mu}_{t}} \\
\lambda_{t} q_{t}=\beta E_{t} \lambda_{t+1}\left[r_{t+1}^{k} u_{t+1}-\Upsilon_{t+1}^{-1} a\left(u_{t+1}\right)+q_{t+1}(1-\delta)\right]
\end{gathered}
$$




$$
\begin{aligned}
& \Upsilon_{t}^{-1} \lambda_{t}=\lambda_{t} q_{t}\left[1-\mathcal{S}\left(\frac{i_{t}}{i_{t-1}}\right)-\left(\frac{i_{t}}{i_{t-1}}\right) \mathcal{S}^{\prime}\left(\frac{i_{t}}{i_{t-1}}\right)\right]+\beta E_{t} \lambda_{t+1} q_{t+1}\left(\frac{i_{t+1}}{i_{t}}\right)^{2} \mathcal{S}^{\prime}\left(\frac{i_{t+1}}{i_{t}}\right) \\
& v_{t}^{2} \ell^{\prime}\left(v_{t}\right)=1-\beta E_{t} \frac{\lambda_{t+1}}{\lambda_{t} \pi_{t+1}} . \\
& r_{t}^{k}=\Upsilon_{t}^{-1} a^{\prime}\left(u_{t}\right) \\
& w_{t}^{i}=\left\{\begin{array}{cl}
\tilde{w}_{t} & \text { if } w_{t}^{i} \text { is set optimally in } t \\
w_{t-1}^{i}\left(\mu_{z^{*}} \pi_{t-1}\right) \tilde{\chi} / \pi_{t} & \text { otherwise }
\end{array},\right.
\end{aligned}
$$

where $\tilde{w}_{t}$ denotes the real wage prevailing in the $1-\tilde{\alpha}$ labor markets in which the union can set wages optimally in period $t$. Let $\tilde{h}_{t}$ denote the level of labor effort supplied to those markets. Because the labor demand curve faced by the union is identical across all labor markets, and because the cost of supplying labor is the same for all markets, one can assume that wage rates, $\tilde{w}_{t}$, and employment, $\tilde{h}_{t}$, are identical across all labor markets updating wages in a given period. By equation (5), we have that $\tilde{w}_{t}^{\tilde{\eta}} \tilde{h}_{t}=w^{\tilde{\eta}} h_{t}^{d}$. It is of use to track the evolution of real wages in a particular labor market. In any labor market $j$ where the wage is set optimally in period $t$, the real wage in that period is $\tilde{w}_{t}$. If in period $t+1$ wages are not reoptimized in that market, the real wage is $\tilde{w}_{t}\left(\mu_{z^{*}} \pi_{t}\right) \tilde{\chi} / \pi_{t+1}$. This is because the nominal wage is indexed by $\tilde{\chi}$ percent of the sum of past price inflation and long-run real wage growth. In general, $s$ periods after the last reoptimization, the real wage is $\tilde{w}_{t} \prod_{k=1}^{s}\left(\frac{\left(\mu_{z^{*}} \pi_{t+k-1}\right) \tilde{\chi}}{\pi_{t+k}}\right)$. To derive the household's first-order condition with respect to the wage rate in those markets where the wage rate is set optimally in the current period, it is convenient to reproduce the parts of the Lagrangian given above that are relevant for this purpose,

$$
\mathcal{L}^{w}=E_{t} \sum_{s=0}^{\infty}(\tilde{\alpha} \beta)^{s} \lambda_{t+s} h_{t+s}^{d} w_{t+s}^{\tilde{\eta}} \prod_{k=1}^{s}\left(\frac{\pi_{t+k}}{\left(\mu_{z^{*}} \pi_{t+k-1}\right) \tilde{\chi}}\right)^{\tilde{\eta}}\left[\tilde{w}_{t}^{1-\tilde{\eta}} \prod_{k=1}^{s}\left(\frac{\pi_{t+k}}{\left(\mu_{z^{*}} \pi_{t+k-1}\right) \tilde{\chi}}\right)^{-1}-\frac{w_{t+s}}{\tilde{\mu}_{t+s}} \tilde{w}_{t}^{-\tilde{\eta}}\right] .
$$

The first-order condition with respect to $\tilde{w}_{t}$ is

$$
0=E_{t} \sum_{s=0}^{\infty}(\beta \tilde{\alpha})^{s} \lambda_{t+s} w_{t+s}^{\tilde{\eta}} h_{t+s}^{d} \prod_{k=1}^{s}\left(\frac{\pi_{t+k}}{\left(\mu_{z^{*}} \pi_{t+k-1}\right)^{\tilde{\chi}}}\right)^{\tilde{\eta}}\left[\frac{\tilde{\eta}-1}{\tilde{\eta}} \frac{\tilde{w}_{t}}{\prod_{k=1}^{s}\left(\frac{\pi_{t+k}}{\left(\mu_{z^{*}} \pi_{t+k-1}\right)^{\chi}}\right)}-\frac{w_{t+s}}{\tilde{\mu}_{t+s}}\right] .
$$

Using equation (12) to eliminate $\tilde{\mu}_{t+s}$, we obtain that the real wage $\tilde{w}_{t}$ must satisfy

$0=E_{t} \sum_{s=0}^{\infty}(\beta \tilde{\alpha})^{s} \lambda_{t+s}\left(\frac{\tilde{w}_{t}}{w_{t+s}}\right)^{-\tilde{\eta}} h_{t+s}^{d} \prod_{k=1}^{s}\left(\frac{\pi_{t+k}}{\left(\mu_{z^{*}} \pi_{t+k-1}\right) \tilde{\chi}}\right)^{\tilde{\eta}}\left[\frac{\tilde{\eta}-1}{\tilde{\eta}} \frac{\tilde{w}_{t}}{\prod_{k=1}^{s}\left(\frac{\pi_{t+k}}{\left(\mu_{z^{*}} \pi_{t+k-1}\right)^{\tilde{\chi}}}\right)}-\frac{-U_{h t+s}}{\lambda_{t+s}}\right]$

This expression states that in labor markets in which the wage rate is reoptimized in period 
$t$, the real wage is set so as to equate the union's future expected average marginal revenue to the average marginal cost of supplying labor. The union's marginal revenue $s$ periods after its last wage reoptimization is given by $\frac{\tilde{\eta}-1}{\tilde{\eta}} \tilde{w}_{t} \prod_{k=1}^{s}\left(\frac{\left(\mu_{z^{*}} \pi_{t+k-1}\right) \tilde{\chi}}{\pi_{t+k}}\right)$. Here, $\tilde{\eta} /(\tilde{\eta}-1)$ represents the markup of wages over marginal cost of labor that would prevail in the absence of wage stickiness. The factor $\prod_{k=1}^{s}\left(\frac{\left(\mu_{z^{*}} \pi_{t+k-1}\right) \tilde{\chi}}{\pi_{t+k}}\right)$ in the expression for marginal revenue reflects the fact that as time goes by without a chance to reoptimize, the real wage declines as the price level increases when wages are imperfectly indexed. In turn, the marginal cost of supplying labor is given by the marginal rate of substitution between consumption and leisure, or $\frac{-U_{h t+s}}{\lambda_{t+s}}=\frac{w_{t+s}}{\tilde{\mu}_{t+s}}$. The variable $\tilde{\mu}_{t}$ is a wedge between the disutility of labor and the average real wage prevailing in the economy. Thus, $\tilde{\mu}_{t}$ can be interpreted as the average markup that unions impose on the labor market. The weights used to compute the average difference between marginal revenue and marginal cost are decreasing in time and increasing in the amount of labor supplied to the market.

We wish to write the wage-setting equation in recursive form. To this end, define

$$
f_{t}^{1}=\left(\frac{\tilde{\eta}-1}{\tilde{\eta}}\right) \tilde{w}_{t} E_{t} \sum_{s=0}^{\infty}(\beta \tilde{\alpha})^{s} \lambda_{t+s}\left(\frac{w_{t+s}}{\tilde{w}_{t}}\right)^{\tilde{\eta}} h_{t+s}^{d} \prod_{k=1}^{s}\left(\frac{\pi_{t+k}}{\left(\mu_{z^{*}} \pi_{t+k-1}\right)^{\tilde{\chi}}}\right)^{\tilde{\eta}-1}
$$

and

$$
f_{t}^{2}=-\tilde{w}_{t}^{-\tilde{\eta}} E_{t} \sum_{s=0}^{\infty}(\beta \tilde{\alpha})^{s} w_{t+s}^{\tilde{\eta}} h_{t+s}^{d} U_{h t+s} \prod_{k=1}^{s}\left(\frac{\pi_{t+k}}{\left(\mu_{z^{*}} \pi_{t+k-1}\right)^{\tilde{\chi}}}\right)^{\tilde{\eta}} .
$$

One can express $f_{t}^{1}$ and $f_{t}^{2}$ recursively as

$$
\begin{gathered}
f_{t}^{1}=\left(\frac{\tilde{\eta}-1}{\tilde{\eta}}\right) \tilde{w}_{t} \lambda_{t}\left(\frac{w_{t}}{\tilde{w}_{t}}\right)^{\tilde{\eta}} h_{t}^{d}+\tilde{\alpha} \beta E_{t}\left(\frac{\pi_{t+1}}{\left(\mu_{z^{*}} \pi_{t}\right) \tilde{\chi}}\right)^{\tilde{\eta}-1}\left(\frac{\tilde{w}_{t+1}}{\tilde{w}_{t}}\right)^{\tilde{\eta}-1} f_{t+1}^{1}, \\
f_{t}^{2}=-U_{h t}\left(\frac{w_{t}}{\tilde{w}_{t}}\right)^{\tilde{\eta}} h_{t}^{d}+\tilde{\alpha} \beta E_{t}\left(\frac{\pi_{t+1}}{\left(\mu_{z^{*}} \pi_{t}\right) \tilde{\chi}}\right)^{\tilde{\eta}}\left(\frac{\tilde{w}_{t+1}}{\tilde{w}_{t}}\right)^{\tilde{\eta}} f_{t+1}^{2} .
\end{gathered}
$$

With these definitions at hand, the wage-setting equation becomes

$$
f_{t}^{1}=f_{t}^{2}
$$

The household's optimality conditions imply a liquidity preference function featuring a negative relation between real balances and the short-term nominal interest rate. To see this, we first note that the absence of arbitrage opportunities in financial markets requires that the gross risk-free nominal interest rate, which we denote by $R_{t}$, be equal to the reciprocal of the price in period $t$ of a nominal security that pays one unit of currency in every state of period $t+1$. Formally, $R_{t}=1 / E_{t} r_{t, t+1}$. This relation together with the household's 
optimality condition (11) implies that

$$
\lambda_{t}=\beta R_{t} E_{t} \frac{\lambda_{t+1}}{\pi_{t+1}}
$$

which is a standard Euler equation for pricing nominally risk-free assets. Combining this expression with equations (10) and (15), we obtain

$$
v_{t}^{2} \ell^{\prime}\left(v_{t}\right)=1-\frac{1}{R_{t}}
$$

The right-hand side of this expression represents the opportunity cost of holding money, which is an increasing function of the nominal interest rate. Given the assumptions regarding the form of the transactions cost function $\ell$, the left-hand side is increasing in money velocity. Thus, this expression defines a liquidity preference function that is decreasing in the nominal interest rate and unit elastic in consumption.

\section{$2.2 \quad$ Firms}

Each variety of final goods is produced by a single firm in a monopolistically competitive environment. Each firm $i \in[0,1]$ produces output using as factor inputs capital services, $k_{i t}$, and labor services, $h_{i t}$. The production technology is given by

$$
F\left(k_{i t}, z_{t} h_{i t}\right)-\psi z_{t}^{*}
$$

where the function $F$ is assumed to be homogenous of degree one, concave, and strictly increasing in both arguments. The variable $z_{t}$ denotes an aggregate, exogenous, and stochastic neutral productivity shock. The parameter $\psi>0$ introduces fixed costs of operating a firm in each period. In turn, the presence of fixed costs implies that the production function exhibits increasing returns to scale. We model fixed costs to ensure a realistic profit-to-output ratio in steady state. Finally, we follow Altig et al. (2005) and assume that fixed costs are subject to permanent shocks, $z_{t}^{*}$, with

$$
\frac{z_{t}^{*}}{z_{t}}=\Upsilon_{t}^{\frac{\theta}{1-\theta}}
$$

This formulation of fixed costs ensures that along the balanced-growth path fixed costs do not vanish. Let $\mu_{z, t} \equiv z_{t} / z_{t-1}$ denote the gross growth rate of the neutral technology shock. By assumption, in the non-stochastic steady state $\mu_{z, t}$ is constant and equal to $\mu_{z}$. Also, let $\hat{\mu}_{z, t}=\ln \left(\mu_{z, t} / \mu_{z}\right)$ denote the percentage deviation of the growth rate of neutral technology 
shocks. Then, the evolution of $\mu_{z, t}$ is assumed to be given by:

$$
\hat{\mu}_{z, t}=\rho_{\mu_{z}} \hat{\mu}_{z, t-1}+\epsilon_{\mu_{z}, t}
$$

with $\epsilon_{\mu_{z}, t} \sim\left(0, \sigma_{\mu_{z}}^{2}\right)$.

Aggregate demand for good $i$, which we denote by $y_{i t}$, is given by

$$
y_{i t}=\left(P_{i t} / P_{t}\right)^{-\eta} y_{t}
$$

where

$$
y_{t} \equiv c_{t}\left[1+\ell\left(v_{t}\right)\right]+g_{t}+\Upsilon_{t}^{-1}\left[i_{t}+a\left(u_{t}\right) k_{t}\right],
$$

denotes aggregate absorption. The variable $g_{t}$ denotes government consumption of the composite good in period $t$.

We rationalize a demand for money by firms by imposing that wage payments be subject to a working-capital requirement that takes the form of a cash-in-advance constraint. Formally, we impose

$$
m_{i t}^{f}=\nu w_{t} h_{i t},
$$

where $m_{i t}^{f}$ denotes the demand for real money balances by firm $i$ in period $t$ and $\nu \geq 0$ is a parameter indicating the fraction of the wage bill that must be backed with monetary assets.

Firms incur financial costs in the amount $\left(1-R_{t}^{-1}\right) m_{i t}^{f}$ stemming from the need to hold money to satisfy the working-capital constraint. Letting the variable $\phi_{i t}$ denote real distributed profits, the period-by-period budget constraint of firm $i$ can then be written as

$$
E_{t} r_{t, t+1} x_{i t+1}^{f}+m_{i t}^{f}-\frac{x_{i t}^{f}+m_{i t-1}^{f}}{\pi_{t}}=\left(\frac{P_{i t}}{P_{t}}\right)^{1-\eta} y_{t}-r_{t}^{k} k_{i t}-w_{t} h_{i t}-\phi_{i t},
$$

where $E_{t} r_{t, t+1} x_{i t+1}^{f}$ denotes the total real cost of one-period state-contingent assets that the firm purchases in period $t$ in terms of the composite good. ${ }^{3}$ We assume that the firm must satisfy demand at the posted price. Formally, we impose

$$
F\left(k_{i t}, z_{t} h_{i t}\right)-\psi z_{t}^{*} \geq\left(\frac{P_{i t}}{P_{t}}\right)^{-\eta} y_{t}
$$

\footnotetext{
${ }^{3}$ Implicit in this specification of the firm's budget constraint is the assumption that firms rent capital services from a centralized market. This is a common assumption in the related literature (e.g., Christiano et al., 2005; Kollmann, 2003; Carlstrom and Fuerst, 2003; and Rotemberg and Woodford, 1992). A polar assumption is that capital is firm specific, as in Woodford (2003, chapter 5.3) and Sveen and Weinke (2003). Both assumptions are clearly extreme. A more realistic treatment of investment dynamics would incorporate a mix of firm-specific and homogeneous capital.
} 
The objective of the firm is to choose contingent plans for $P_{i t}, h_{i t}, k_{i t}, x_{i t+1}^{f}$, and $m_{i t}^{f}$ so as to maximize the present discounted value of dividend payments, given by

$$
E_{t} \sum_{s=0}^{\infty} r_{t, t+s} P_{t+s} \phi_{i t+s}
$$

where $r_{t, t+s} \equiv \prod_{k=1}^{s} r_{t+k-1, t+k}$, for $s \geq 1$, denotes the stochastic nominal discount factor between $t$ and $t+s$, and $r_{t, t} \equiv 1$. Firms are assumed to be subject to a borrowing constraint that prevents them from engaging in Ponzi games.

Clearly, because $r_{t, t+s}$ represents both the firm's stochastic discount factor and the market pricing kernel for financial assets, and because the firm's objective function is linear in asset holdings, it follows that any asset accumulation plan of the firm satisfying the no-Ponzi constraint is optimal. Suppose, without loss of generality, that the firm manages its portfolio so that its financial position at the beginning of each period is nil. Formally, assume that $x_{i t+1}^{f}+m_{i t}^{f}=0$ at all dates and states. Note that this financial strategy makes $x_{i t+1}^{f}$ state noncontingent. In this case, distributed dividends take the form

$$
\phi_{i t}=\left(\frac{P_{i t}}{P_{t}}\right)^{1-\eta} y_{t}-r_{t}^{k} k_{i t}-w_{t} h_{i t}-\left(1-R_{t}^{-1}\right) m_{i t}^{f} .
$$

For this expression to hold in period zero, we impose the initial condition $x_{i 0}^{f}+m_{i-1}^{f}=0$. The last term on the right-hand side of the above expression for dividends represents the firm's financial costs associated with the cash-in-advance constraint on wages. This financial cost is increasing in the opportunity cost of holding money, $1-R_{t}^{-1}$, which in turn is an increasing function of the short-term nominal interest rate $R_{t}$.

Letting $r_{t, t+s} P_{t+s} \mathrm{mc}_{i t+s}$ denote the Lagrange multiplier associated with constraint (23), the first-order conditions of the firm's maximization problem with respect to capital and labor services are, respectively,

$$
\mathrm{mc}_{i t} z_{t} F_{2}\left(k_{i t}, z_{t} h_{i t}\right)=w_{t}\left[1+\nu \frac{R_{t}-1}{R_{t}}\right]
$$

and

$$
\mathrm{mc}_{i t} F_{1}\left(k_{i t}, z_{t} h_{i t}\right)=r_{t}^{k}
$$

It is clear from these optimality conditions that the presence of a working-capital requirement introduces a financial cost of labor that is increasing in the nominal interest rate. We note also that because all firms face the same factor prices and because they all have access to the same production technology with the function $F$ being linearly homogeneous, marginal 
costs, $\mathrm{mc}_{i t}$, are identical across firms. Indeed, because the above first-order conditions hold for all firms independently of whether they are allowed to reset prices optimally, marginal costs are identical across all firms in the economy.

Prices are assumed to be sticky à la Calvo (1983) and Yun (1996). Specifically, each period $t \geq 0$ a fraction $\alpha \in[0,1)$ of randomly picked firms is not allowed to optimally set the nominal price of the good they produce. Instead, these firms index their prices to past inflation according to the rule $P_{i t}=P_{i t-1} \pi_{t-1}^{\chi}$. The interpretation of the parameter $\chi$ is the similar to that of its wage counterpart $\tilde{\chi}$. The remaining $1-\alpha$ firms choose prices optimally. Consider the price-setting problem faced by a firm that has the opportunity to reoptimize the price in period $t$. This price, which we denote by $\tilde{P}_{t}$, is set so as to maximize the expected present discounted value of profits. That is, $\tilde{P}_{t}$ maximizes the following Lagrangian:

$$
\begin{aligned}
& \mathcal{L}= E_{t} \sum_{s=0}^{\infty} r_{t, t+s} P_{t+s} \alpha^{s}\left\{\left(\frac{\tilde{P}_{t}}{P_{t}}\right)^{1-\eta} \prod_{k=1}^{s}\left(\frac{\pi_{t+k-1}^{\chi}}{\pi_{t+k}}\right)^{1-\eta} y_{t+s}-r_{t+s}^{k} k_{i t+s}-w_{t+s} h_{i t+s}\left[1+\nu\left(1-R_{t+s}^{-1}\right)\right]\right. \\
&\left.+\mathrm{mc}_{i t+s}\left[F\left(k_{i t+s}, z_{t+s} h_{i t+s}\right)-\psi z_{t+s}^{*}-\left(\frac{\tilde{P}_{t}}{P_{t}}\right)^{-\eta} \prod_{k=1}^{s}\left(\frac{\pi_{t+k-1}^{\chi}}{\pi_{t+k}}\right)^{-\eta} y_{t+s}\right]\right\} .
\end{aligned}
$$

The first-order condition with respect to $\tilde{P}_{t}$ is

$E_{t} \sum_{s=0}^{\infty} r_{t, t+s} P_{t+s} \alpha^{s}\left(\frac{\tilde{P}_{t}}{P_{t}}\right)^{-\eta} \prod_{k=1}^{s}\left(\frac{\pi_{t+k-1}^{\chi}}{\pi_{t+k}}\right)^{-\eta} y_{t+s}\left[\frac{\eta-1}{\eta}\left(\frac{\tilde{P}_{t}}{P_{t}}\right) \prod_{k=1}^{s}\left(\frac{\pi_{t+k-1}^{\chi}}{\pi_{t+k}}\right)-m c_{i t+s}\right]=0$.

According to this expression, optimizing firms set nominal prices so as to equate average future expected marginal revenues to average future expected marginal costs. The weights used in calculating these averages are decreasing with time and increasing in the size of the demand for the good produced by the firm. Under flexible prices $(\alpha=0)$, the above optimality condition reduces to a static relation equating marginal costs to marginal revenues period by period.

It will prove useful to express this first-order condition recursively. To that end, let

$$
x_{t}^{1} \equiv E_{t} \sum_{s=0}^{\infty} r_{t, t+s} \alpha^{s} y_{t+s} m c_{i t+s}\left(\frac{\tilde{P}_{t}}{P_{t}}\right)^{-\eta-1} \prod_{k=1}^{s}\left(\frac{\pi_{t+k-1}^{\chi}}{\pi_{t+k}^{(1+\eta) / \eta}}\right)^{-\eta}
$$

and

$$
x_{t}^{2} \equiv E_{t} \sum_{s=0}^{\infty} r_{t, t+s} \alpha^{s} y_{t+s}\left(\frac{\tilde{P}_{t}}{P_{t}}\right)^{-\eta} \prod_{k=1}^{s}\left(\frac{\pi_{t+k-1}^{\chi}}{\pi_{t+k}^{\eta /(\eta-1)}}\right)^{1-\eta}
$$


Express $x_{t}^{1}$ and $x_{t}^{2}$ recursively as

$$
\begin{gathered}
x_{t}^{1}=y_{t} \mathrm{mc}_{t} \tilde{p}_{t}^{-\eta-1}+\alpha \beta E_{t} \frac{\lambda_{t+1}}{\lambda_{t}}\left(\tilde{p}_{t} / \tilde{p}_{t+1}\right)^{-\eta-1}\left(\frac{\pi_{t}^{\chi}}{\pi_{t+1}}\right)^{-\eta} x_{t+1}^{1}, \\
x_{t}^{2}=y_{t} \tilde{p}_{t}^{-\eta}+\alpha \beta E_{t} \frac{\lambda_{t+1}}{\lambda_{t}}\left(\frac{\pi_{t}^{\chi}}{\pi_{t+1}}\right)^{1-\eta}\left(\frac{\tilde{p}_{t}}{\tilde{p}_{t+1}}\right)^{-\eta} x_{t+1}^{2} .
\end{gathered}
$$

Then we can write the first-order condition with respect to $\tilde{P}_{t}$ as

$$
\eta x_{t}^{1}=(\eta-1) x_{t}^{2} .
$$

The labor input used by firm $i \in[0,1]$, denoted $h_{i t}$, is assumed to be a composite made of a continuum of differentiated labor services, $h_{i t}^{j}$ indexed by $j \in[0,1]$. Formally,

$$
h_{i t}=\left[\int_{0}^{1} h_{i t}^{j 1-1 / \tilde{\eta}} d j\right]^{1 /(1-1 / \tilde{\eta})},
$$

where the parameter $\tilde{\eta}>1$ denotes the intratemporal elasticity of substitution across different types of activities. For any given level of $h_{i t}$, the demand for each variety of labor $j \in[0,1]$ in period $t$ must solve the dual problem of minimizing total labor cost, $\int_{0}^{1} W_{t}^{j} h_{i t}^{j} d j$, subject to the aggregation constraint (31), where $W_{t}^{j}$ denotes the nominal wage rate paid to labor of variety $j$ at time $t$. The optimal demand for labor of type $j$ is then given by

$$
h_{i t}^{j}=\left(\frac{W_{t}^{j}}{W_{t}}\right)^{-\tilde{\eta}} h_{i t},
$$

where $W_{t}$ is a nominal wage index given by

$$
W_{t} \equiv\left[\int_{0}^{1} W_{t}^{j 1-\tilde{\eta}} d j\right]^{\frac{1}{1-\tilde{\eta}}} .
$$

This wage index has the property that the minimum cost of a bundle of intermediate labor inputs yielding $h_{i t}$ units of the composite labor is given by $W_{t} h_{i t}$.

\subsection{The Government}

Each period, the government consumes $g_{t}$ units of the composite good. We assume that the government minimizes the cost of producing $g_{t}$. As a result, public demand for each variety $i \in[0,1]$ of differentiated goods $g_{i t}$ is given by $g_{i t}=\left(P_{i t} / P_{t}\right)^{-\eta} g_{t}$. 
We assume that along the balanced-growth path the share of government spending in value added is constant, that is, we impose $\lim _{j \rightarrow \infty} E_{t} g_{t+j} / y_{t+j}=s_{g}$, where $s_{g}$ is a constant indicating the share of government consumption in value added. To this end we impose:

$$
g_{t}=z_{t}^{*} \bar{g}_{t}
$$

where $\bar{g}_{t}$ is an exogenous stationary stochastic process. This assumption ensures that government purchases and output are cointegrated. We impose the following law of motion for $\bar{g}_{t}:$

$$
\ln \left(\frac{\bar{g}_{t}}{\bar{g}}\right)=\rho_{\bar{g}} \ln \left(\frac{\bar{g}_{t-1}}{\bar{g}}\right)+\epsilon_{\bar{g}, t}
$$

The government issues money given in real terms by $m_{t} \equiv m_{t}^{h}+\int_{0}^{1} m_{i t}^{f} d i$. For simplicity, we assume that government debt is zero at time zero and that the fiscal authority levies lumpsum taxes, $\tau_{t}$ to bridge any gap between seignorage income and government expenditures, that is, $\tau_{t}=g_{t}-\left(m_{t}-m_{t-1} / \pi_{t}\right)$. As a consequence, government debt is nil at all times.

We postpone the presentation of the monetary policy regime until after we characterize a competitive equilibrium.

\subsection{Aggregation}

We limit attention to a symmetric equilibrium in which all firms that have the opportunity to change their price optimally at a given time choose the same price. It then follows from (4) that the aggregate price index can be written as $P_{t}^{1-\eta}=\alpha\left(P_{t-1} \pi_{t-1}^{\chi}\right)^{1-\eta}+(1-\alpha) \tilde{P}_{t}^{1-\eta}$. Dividing this expression through by $P_{t}^{1-\eta}$ one obtains

$$
1=\alpha \pi_{t}^{\eta-1} \pi_{t-1}^{\chi(1-\eta)}+(1-\alpha) \tilde{p}_{t}^{1-\eta}
$$

\subsubsection{Market Clearing in the Final Goods Market}

Naturally, the set of equilibrium conditions includes a resource constraint. Such a restriction is typically of the type $F\left(k_{t}, z_{t} h_{t}\right)-\psi z_{t}^{*}=c_{t}\left[1+\ell\left(v_{t}\right)\right]+g_{t}+\Upsilon_{t}^{-1}\left[i_{t}+a\left(u_{t}\right) k_{t}\right]$. In the present model, however, this restriction is not valid. This is because the model implies relative price dispersion across varieties. This price dispersion, which is induced by the assumed nature of price stickiness, is inefficient and entails output loss. To see this, consider the following expression stating that supply must equal demand at the firm level:

$$
F\left(k_{i t}, z_{t} h_{i t}\right)-\psi z_{t}^{*}=\left\{\left[1+\ell\left(v_{t}\right)\right] c_{t}+g_{t}+\Upsilon_{t}^{-1}\left[i_{t}+a\left(u_{t}\right) k_{t}\right]\right\}\left(\frac{P_{i t}}{P_{t}}\right)^{-\eta}
$$


Integrating over all firms and taking into account that (a) the capital-labor ratio is common across firms, (b) that the aggregate demand for the composite labor input, $h_{t}^{d}$, satisfies

$$
h_{t}^{d}=\int_{0}^{1} h_{i t} d i
$$

and that (c) the aggregate effective level of capital, $u_{t} k_{t}$ satisfies

$$
u_{t} k_{t}=\int_{0}^{1} k_{i t} d i
$$

we obtain

$$
z_{t} h_{t}^{d} F\left(\frac{u_{t} k_{t}}{z_{t} h_{t}^{d}}, 1\right)-\psi z_{t}^{*}=\left\{\left[1+\ell\left(v_{t}\right)\right] c_{t}+g_{t}+\Upsilon_{t}^{-1}\left[i_{t}+a\left(u_{t}\right) k_{t}\right]\right\} \int_{0}^{1}\left(\frac{P_{i t}}{P_{t}}\right)^{-\eta} d i
$$

Let $s_{t} \equiv \int_{0}^{1}\left(\frac{P_{i t}}{P_{t}}\right)^{-\eta} d i$. Then we have

$$
\begin{aligned}
s_{t} & =\int_{0}^{1}\left(\frac{P_{i t}}{P_{t}}\right)^{-\eta} d i \\
& =(1-\alpha)\left(\frac{\tilde{P}_{t}}{P_{t}}\right)^{-\eta}+(1-\alpha) \alpha\left(\frac{\tilde{P}_{t-1} \pi_{t-1}^{\chi}}{P_{t}}\right)^{-\eta}+(1-\alpha) \alpha^{2}\left(\frac{\tilde{P}_{t-2} \pi_{t-1}^{\chi} \pi_{t-2}^{\chi}}{P_{t}}\right)^{-\eta}+\ldots \\
& =(1-\alpha) \sum_{j=0}^{\infty} \alpha^{j}\left(\frac{\tilde{P}_{t-j} \prod_{s=1}^{j} \pi_{t-j-1+s}^{\chi}}{P_{t}}\right)^{\eta} \\
& =(1-\alpha) \tilde{p}_{t}^{-\eta}+\alpha\left(\frac{\pi_{t}}{\pi_{t-1}^{\chi}}\right)^{\eta} s_{t-1} .
\end{aligned}
$$

Summarizing, the resource constraint in the present model is given by the following two expressions

$$
F\left(u_{t} k_{t}, z_{t} h_{t}^{d}\right)-\psi z_{t}^{*}=\left\{\left[1+\ell\left(v_{t}\right)\right] c_{t}+g_{t}+\Upsilon_{t}^{-1}\left[i_{t}+a\left(u_{t}\right) k_{t}\right]\right\} s_{t}
$$

and

$$
s_{t}=(1-\alpha) \tilde{p}_{t}^{-\eta}+\alpha\left(\frac{\pi_{t}}{\pi_{t-1}^{\chi}}\right)^{\eta} s_{t-1},
$$

with $s_{-1}$ given. The state variable $s_{t}$ summarizes the resource costs induced by the inefficient price dispersion featured in the Calvo model in equilibrium. Three observations are in order about the price dispersion measure $s_{t}$. First, $s_{t}$ is bounded below by 1 . That is, price dispersion is always a costly distortion in this model. To see that $s_{t}$ is bounded below by 1 , 
let $v_{i t} \equiv\left(P_{i t} / P_{t}\right)^{1-\eta}$. It follows from the definition of the price index given in equation (4) that $\left[\int_{0}^{1} v_{i t}\right]^{\eta /(\eta-1)}=1$. Also, by definition we have $s_{t}=\int_{0}^{1} v_{i t}^{\eta /(\eta-1)}$. Then, taking into account that $\eta /(\eta-1)>1$, Jensen's inequality implies that $1=\left[\int_{0}^{1} v_{i t}\right]^{\eta /(\eta-1)} \leq \int_{0}^{1} v_{i t}^{\eta /(\eta-1)}=s_{t}$. Second, in an economy where the non-stochastic level of inflation is nil (i.e., when $\pi=1$ ) or where prices are fully indexed to any variable $\omega_{t}$ with the property that its deterministic steady-state level equals the deterministic steady-state value of inflation (i.e., $\omega=\pi$ ), then the variable $s_{t}$ follows, up to first order, the univariate autoregressive process $\hat{s}_{t}=\alpha \hat{s}_{t-1}$. In these cases, the price dispersion measure $s_{t}$ has no first-order real consequences for the stationary distribution of any endogenous variable of the model. This means that studies that restrict attention to linear approximations to the equilibrium conditions are justified to ignore the variable $s_{t}$ if the model features no price dispersion in the deterministic steady state. But $s_{t}$ matters up to first order when the deterministic steady state features movements in relative prices across goods varieties. More importantly, the price dispersion variable $s_{t}$ must be taken into account if one is interested in higher-order approximations to the equilibrium conditions even if relative prices are stable in the deterministic steady state. Omitting $s_{t}$ in higher-order expansions would amount to leaving out certain higher-order terms while including others. Finally, when prices are fully flexible, $\alpha=0$, we have that $\tilde{p}_{t}=1$ and thus $s_{t}=1$. (Obviously, in a flexible-price equilibrium there is no price dispersion across varieties.)

As discussed above, equilibrium marginal costs and capital-labor ratios are identical across firms. Therefore, one can aggregate the firm's optimality conditions with respect to labor and capital, equations (25) and (26), as

$$
\mathrm{mc}_{t} z_{t} F_{2}\left(u_{t} k_{t}, z_{t} h_{t}^{d}\right)=w_{t}\left[1+\nu \frac{R_{t}-1}{R_{t}}\right]
$$

and

$$
\mathrm{mc}_{t} F_{1}\left(u_{t} k_{t}, z_{t} h_{t}^{d}\right)=r_{t}^{k}
$$

\subsubsection{Market Clearing in the Labor Market}

It follows from equation (32) that the aggregate demand for labor of type $j \in[0,1]$, which we denote by $h_{t}^{j} \equiv \int_{0}^{1} h_{i t}^{j} d i$, is given by

$$
h_{t}^{j}=\left(\frac{W_{t}^{j}}{W_{t}}\right)^{-\tilde{\eta}} h_{t}^{d},
$$


where $h_{t}^{d} \equiv \int_{0}^{1} h_{i t} d i$ denotes the aggregate demand for the composite labor input. Taking into account that at any point in time the nominal wage rate is identical across all labor markets at which wages are allowed to change optimally, we have that labor demand in each of those markets is

$$
\tilde{h}_{t}=\left(\frac{\tilde{w}_{t}}{w_{t}}\right)^{-\tilde{\eta}} h_{t}^{d}
$$

Combining this expression with equation (39), describing the demand for labor of type $j \in[0,1]$, and with the time constraint (6), which must hold with equality, we can write

$$
h_{t}=(1-\tilde{\alpha}) h_{t}^{d} \sum_{s=0}^{\infty} \tilde{\alpha}^{s}\left(\frac{\tilde{W}_{t-s} \prod_{k=1}^{s}\left(\mu_{z^{*}} \pi_{t+k-s-1}\right) \tilde{\chi}}{W_{t}}\right)^{-\tilde{\eta}}
$$

Let $\tilde{s}_{t} \equiv(1-\tilde{\alpha}) \sum_{s=0}^{\infty} \tilde{\alpha}^{s}\left(\frac{\tilde{W}_{t-s} \prod_{k=1}^{s}\left(\mu_{z^{*}} \pi_{t+k-s-1}\right) \tilde{\chi}}{W_{t}}\right)^{-\tilde{\eta}}$. The variable $\tilde{s}_{t}$ measures the degree of wage dispersion across different types of labor. The above expression can be written as

$$
h_{t}=\tilde{s}_{t} h_{t}^{d}
$$

The state variable $\tilde{s}_{t}$ evolves over time according to

$$
\tilde{s}_{t}=(1-\tilde{\alpha})\left(\frac{\tilde{w}_{t}}{w_{t}}\right)^{-\tilde{\eta}}+\tilde{\alpha}\left(\frac{w_{t-1}}{w_{t}}\right)^{-\tilde{\eta}}\left(\frac{\pi_{t}}{\left(\mu_{z^{*}} \pi_{t-1}\right) \tilde{\chi}}\right)^{\tilde{\eta}} \tilde{s}_{t-1} .
$$

We note that because all job varieties are ex-ante identical, any wage dispersion is inefficient. This is reflected in the fact that $\tilde{s}_{t}$ is bounded below by 1 . The proof of this statement is identical to that offered earlier for the fact that $s_{t}$ is bounded below by unity. To see this, note that $\tilde{s}_{t}$ can be written as $\tilde{s}_{t}=\int_{0}^{1}\left(\frac{W_{i t}}{W_{t}}\right)^{-\tilde{\eta}} d i$. This inefficiency introduces a wedge that makes the number of hours supplied to the market, $h_{t}$, larger than the number of productive units of labor input, $h_{t}^{d}$. In an environment without long-run wage dispersion, the dead-weight loss created by wage dispersion is nil up to first order. Formally, a first-order approximation of the law of motion of $\tilde{s}_{t}$ yields a univariate autoregressive process of the form $\hat{\tilde{s}}_{t}=\tilde{\alpha} \hat{\tilde{s}}_{t-1}$, as long as there is no wage dispersion in the deterministic steady state. When wages are fully flexible, $\tilde{\alpha}=0$, wage dispersion disappears, and thus $\tilde{s}_{t}$ equals 1 .

It follows from our definition of the wage index given in equation (33) that in equilibrium the real wage rate must satisfy

$$
w_{t}^{1-\tilde{\eta}}=(1-\tilde{\alpha}) \tilde{w}_{t}^{1-\tilde{\eta}}+\tilde{\alpha} w_{t-1}^{1-\tilde{\eta}}\left(\frac{\left(\mu_{z^{*}} \pi_{t-1}\right)^{\tilde{\chi}}}{\pi_{t}}\right)^{1-\tilde{\eta}}
$$


Aggregating the expression for firm's profits given in equation (24) yields

$$
\phi_{t}=y_{t}-r_{t}^{k} u_{t} k_{t}-w_{t} h_{t}^{d}-\nu\left(1-R_{t}^{-1}\right) w_{t} h_{t}^{d}
$$

In equilibrium, real money holdings can be expressed as

$$
m_{t}=m_{t}^{h}+\nu w_{t} h_{t}^{d}
$$

and the government budget constraint is given by

$$
\tau_{t}=g_{t}-\left(m_{t}-m_{t-1} / \pi_{t}\right) .
$$

\subsection{Functional Forms}

We use the following standard functional forms for utility and technology:

$$
U=\frac{\left[\left(c_{t}-b c_{t-1}\right)^{1-\phi_{4}}\left(1-h_{t}\right)^{\phi_{4}}\right]^{1-\phi_{3}}-1}{1-\phi_{3}}
$$

and

$$
F(k, h)=k^{\theta} h^{1-\theta} .
$$

The functional form for the investment adjustment cost function is taken from Christiano, Eichenbaum, and Evans (2005):

$$
\mathcal{S}\left(\frac{i_{t}}{i_{t-1}}\right)=\frac{\kappa}{2}\left(\frac{i_{t}}{i_{t-1}}-\mu_{I}\right)^{2},
$$

where $\mu_{I}$ is the steady-state growth rate of investment.

Following Schmitt-Grohé and Uribe (2004a,b) we assume that the transaction cost technology takes the form

$$
\ell(v)=\phi_{1} v+\phi_{2} / v-2 \sqrt{\phi_{1} \phi_{2}} .
$$

The money demand function implied by the above transaction technology is of the form

$$
v_{t}^{2}=\frac{\phi_{2}}{\phi_{1}}+\frac{1}{\phi_{1}} \frac{R_{t}-1}{R_{t}}
$$

Note the existence of a satiation point for consumption-based money velocity, $\underline{v}$, equal to $\sqrt{\phi_{2} / \phi_{1}}$. Also, the implied money demand is unit elastic with respect to consumption expenditures. This feature is a consequence of the assumption that transaction costs, $c \ell(c / m)$, are 
homogenous of degree one in consumption and real balances and is independent of the particular functional form assumed for $\ell(\cdot)$. Further, as the parameter $\phi_{2}$ approaches zero, the transaction cost function $\ell(\cdot)$ becomes linear in velocity and the demand for money adopts the Baumol-Tobin square root form with respect to the opportunity cost of holding money, $(R-1) / R$. That is, the log-log elasticity of money demand with respect to the opportunity cost of holding money converges to $1 / 2$, as $\phi_{2}$ vanishes.

The costs of higher capacity utilization are parameterized as follows:

$$
a(u)=\gamma_{1}(u-1)+\frac{\gamma_{2}}{2}(u-1)^{2}
$$

\subsection{Inducing Stationarity}

This economy features two types of permanent shocks. As a result, a number of variables, such as output and the real wage, will not be stationary along the balanced-growth path. We therefore perform a change of variables so as to obtain a set of equilibrium conditions that involve only stationary variables. To this end we note that the variables $c_{t}, m_{t}^{h}, m_{t}$, $w_{t}, \tilde{w}_{t}, y_{t}, g_{t}, \phi_{t}, x_{t}^{1}, x_{t}^{2}$, and $\tau_{t}$ are cointegrated with $z_{t}^{*}$. Similarly, the variables $k_{t+1}$ and $i_{t}$ are cointegrated with $\Upsilon_{t} z_{t}^{*}$, the variable $\lambda_{t}$ is cointegrated with $z_{t}^{*\left(1-\phi_{3}\right)\left(1-\phi_{4}\right)-1}$, the variables $q_{t}$ and $r_{t}^{k}$ are cointegrated with $1 / \Upsilon_{t}$, and the variables $f_{t}^{1}$ and $f_{t}^{2}$ are cointegrated with $z_{t}^{*\left(1-\phi_{3}\right)\left(1-\phi_{4}\right)}$. We therefore divide these variables by the appropriate cointegrating factor and denote the corresponding stationary variables with capital letters.

\subsection{Competitive Equilibrium}

A stationary competitive equilibrium is a set of stationary processes $u_{t}, C_{t}, h_{t}, I_{t}, K_{t+1}$, $v_{t}, M_{t}^{h}, M_{t}, \Lambda_{t}, \pi_{t}, W_{t}, \tilde{\mu}_{t}, Q_{t}, R_{t}^{k}, \Phi_{t}, F_{t}^{1}, F_{t}^{2}, \tilde{W}_{t}, h_{t}^{d}, Y_{t}, \mathrm{mc}_{t}, X_{t}^{1}, X_{t}^{2}, \tilde{p}_{t}, s_{t}, \tilde{s}_{t}$, and $T_{t}$ satisfying (7), (8), (10), (12)-(21), (28)-(30), (34)-(38), and (40)-(45) written in terms of the stationary variables, given exogenous stochastic processes $\mu_{\Upsilon, t}, \mu_{z, t}$, and $\bar{g}_{t}$, the policy process, $R_{t}$, and initial conditions $c_{-1}, w_{-1}, s_{-1}, \tilde{s}_{-1}, \pi_{-1}, i_{-1}$, and $k_{0}$. A complete list of the competitive equilibrium conditions in terms of stationary variables is given in the technical appendix to this paper (Schmitt-Grohé and Uribe, 2005b).

\subsection{Ramsey Equilibrium}

We assume that at $t=0$ the benevolent government has been operating for an infinite number of periods. In choosing optimal policy, the government is assumed to honor commitments made in the past. This form of policy commitment has been referred to as 'optimal from the timeless perspective' (Woodford, 2003). 
Formally, we define a Ramsey equilibrium as a set of stationary processes $u_{t}, C_{t}, h_{t}, I_{t}$, $K_{t+1}, v_{t}, M_{t}^{h}, M_{t}, \Lambda_{t}, \pi_{t}, W_{t}, \tilde{\mu}_{t}, Q_{t}, R_{t}^{k}, \Phi_{t}, F_{t}^{1}, F_{t}^{2}, \tilde{W}_{t}, h_{t}^{d}, Y_{t}, \mathrm{mc}_{t}, X_{t}^{1}, X_{t}^{2}, \tilde{p}_{t}, s_{t}, \tilde{s}_{t}, T_{t}$, and $R_{t}$ for $t \geq 0$ that maximize

$$
E_{0} \sum_{t=0}^{\infty} \beta^{t} \frac{\left(z_{0}^{*} \prod_{s=1}^{t} \mu_{z^{*}, s}\right)^{\left(1-\phi_{4}\right)\left(1-\phi_{3}\right)}\left[\left(C_{t}-b \frac{C_{t-1}}{\mu_{z^{*}, t}}\right)^{1-\phi_{4}}\left(1-h_{t}\right)^{\phi_{4}}\right]^{1-\phi_{3}}-1}{1-\phi_{3}}
$$

subject to the competitive equilibrium conditions (7), (8), (10), (12)-(21), (28)-(30), (34)(38), and (40)-(45) written in stationary variables, and $R_{t} \geq 1$, for $t>-\infty$, given exogenous stochastic processes $\mu_{z, t}, \mu_{\Upsilon, t}$, and $\bar{g}_{t}$, values of the variables listed above dated $t<0$, and values of the Lagrange multipliers associated with the constraints listed above dated $t<0$.

Technically, the difference between the usual Ramsey equilibrium concept and the one employed here is that here the structure of the optimality conditions associated with the Ramsey equilibrium is time invariant. By contrast, under the standard Ramsey equilibrium definition, the equilibrium conditions in the initial periods are different from those applying to later periods.

Our approach to analyzing the business-cycle properties of Ramsey-optimal policy is comparable to that in the existing literature under the standard definition of Ramsey optimality (e.g., Chari, Christiano, and Kehoe, 1995). The reason is that existing studies of business cycles under the standard Ramsey policy focus on the behavior of the economy in the stochastic steady state (i.e., they limit attention to the properties of equilibrium time series excluding the initial transition).

\section{Calibration}

The time unit is meant to be one quarter. For most of the calibration we draw on the paper by Altig et al. (2005) (hereafter ACEL). We assign most of the parameter values from the 'high-markup' case of the ACEL estimation results. In this case, the steady-state markup in product markets is 20 percent (or $\eta=6$ ).

Following ACEL, we assume that in the deterministic steady state of the competitive equilibrium the rate of capacity utilization equals one $(u=1)$ and profits are zero $(\phi=$ $0)$. ACEL calibrate the discount factor, $\beta$, to be $1.03^{-1 / 4}$, the depreciation rate, $\delta$, to be 0.025 , and the capital share, $\theta$, to be 0.36 . ACEL assume that preferences are separable in consumption and leisure and logarithmic in habit-adjusted consumption $\left(\phi_{3}=1\right)$. Their assumed functional form for the period utility function implies a unit Frisch elasticity of labor supply. ACEL assume a steady-state markup of wages over the marginal rate of substitution 
between leisure and consumption of 5 percent (or $\tilde{\eta}=21$ ).

ACEL estimate the degree of nominal wage stickiness to be slightly above 3 quarters $(\tilde{\alpha}=0.69)$. They also estimate the degree of habit formation measured by the parameter $b$ to be 0.69 , the elasticity of the marginal capital adjustment cost, $\kappa$, to be 2.79 , the elasticity of the marginal cost of capacity utilization, $\gamma_{2} / \gamma_{1}$, to be 1.46 , and the annualized interest semielasticity of money demand by households, $(1 / 4) \partial \ln \left(m_{t}^{h}\right) / \partial\left(R_{t}\right)$, to be -0.81 .

ACEL estimate the parameters of the exogenous stochastic processes for the investmentspecific and neutral technology shocks $\mu_{\Upsilon, t}$ and $\mu_{z, t}$ to be, respectively, $\left(\mu_{\Upsilon}, \sigma_{\mu_{\Upsilon}}, \rho_{\mu_{\Upsilon}}\right)=$ $(1.0042,0.0031,0.20)$ and $\left(\mu_{z}, \sigma_{\mu_{z}}, \rho_{\mu_{z}}\right)=(1.00213,0.0007,0.89)$.

ACEL estimate the degree of price stickiness to be 5 quarters (or $\alpha=0.8$ ) when capital is not firm specific, which is the assumption maintained in this paper.

We do not draw from the work of ACEL to calibrate the degree of indexation in product prices and wages. The reason is that in their study the parameters governing the degree of indexation are not estimated. They simply assume full indexation of all prices to past product price inflation. Instead, we draw from the econometric work of Cogley and Sbordone (2005) and Levin et al. (2005) who find no evidence of indexation in product prices. We therefore set $\chi=0$. At the same time, Levin et al. estimate a high degree of indexation in nominal wages. We therefore assume that $\tilde{\chi}=1$, which happens to be the value assumed in ACEL.

Following Christiano, Eichenbaum, and Evans (2005), hereafter CEE, we set the steadystate share of money held by households, $m^{h} / m$, to 0.44 . Using postwar U.S. data, we measure the average money-to-output ratio as the ratio of M1 to GDP, and set it equal to 17 percent per year. Neither ACEL nor CEE impose this calibration restriction. Instead, they assume that all of the wage bill is subject to a cash-in-advance constraint-i.e., they impose $\nu=1$. By contrast, our calibration implies that only 60 percent of wage payments must be held in money (or $\nu=0.6$ ).

In calibrating the model we assume that in the deterministic steady state of the competitive equilibrium the rate of inflation equals 4.2 percent per year. This value coincides with the average growth rate of the U.S. postwar GDP deflator.

ACEL do not consider government purchases shocks. One study that estimates the process for government purchases in the context of a model similar to the one we are studying is Ravn (2005) and we use his findings to calibrate this process. Specifically, Ravn estimates $\rho_{g}=0.9$ and $\sigma_{\epsilon^{g}}=0.008$. Finally, we impose that the steady-state share of government consumption in value added is 17 percent, which equals the average value observed in the United States over the postwar period.

Table 1 presents the values of the deep structural parameters implied by our calibration 
strategy.

\section{The Ramsey Steady State}

In this section, we characterize the long-run state of the Ramsey equilibrium in an economy without uncertainty. We refer to this state as the Ramsey steady state. Note that the Ramsey steady state is in general different from the allocation/policy that maximizes welfare in the steady state of a competitive equilibrium.

In most existing studies on optimal monetary policy in economies with neo-Keynesian features, the task of characterizing the Ramsey steady state is trivial. The reason is that these studies assume the existence of a single nominal distortion, namely sluggish adjustment in nominal product or factor prices or both. In this case, the optimal rate of inflation in the Ramsey steady state is nil. By contrast, the economy studied in this paper features additional nominal frictions in the form of money demand by households and firms. This feature complicates the computation of the Ramsey steady state in the context of the rich theoretical environment studied in this paper.

Two exceptions to the common practice of abstracting from money demand in analysis of optimal monetary policy in the neo-Keynesian model are Khan et al. (2003) and Schmitt-Grohé and Uribe (2004a). In both of these studies, the computation of the Ramsey steady state is relatively straight forward because of the simplicity of the theoretical structures considered. In particular, neither study features wage stickiness, capital accumulation, habit formation, variable capacity utilization, or factor adjustment costs. When all of these complications are added, it becomes virtually impossible to characterize the Ramsey steady state conditions analytically. A contribution of the research project to which this paper belongs is the development of a general algorithm to characterize and numerically solve the Ramsey equilibrium in medium-scale macroeconomic models. This algorithm yields an exact numerical solution for the Ramsey steady-state equilibrium.

\subsection{Price Stickiness and the Optimal Inflation Rate}

We find that the most striking characteristic of the Ramsey steady state is the high sensitivity of the optimal rate of inflation with respect to the parameter governing the degree of price stickiness, $\alpha$, for the range of values of this parameter that is empirically relevant.

Available empirical estimates of the degree of price rigidity using macroeconomic data vary from 2 to 5 quarters, or $\alpha \in[0.5,0.8]$. For example, CEE (2005) in the context of a model similar to ours estimate $\alpha$ to be 0.6. By contrast, ACEL (2005), using a model 
Table 1: Structural Parameters

\begin{tabular}{|c|c|c|}
\hline Parameter & Value & Description \\
\hline$\beta$ & $1.03^{1 / 4}$ & Subjective discount factor (quarterly) \\
\hline$\theta$ & 0.36 & Share of capital in value added \\
\hline$\psi$ & 0.25 & Fixed cost parameter \\
\hline$\delta$ & 0.025 & Depreciation rate (quarterly) \\
\hline$\nu$ & 0.6011 & Fraction of wage bill subject to a CIA constraint \\
\hline$\eta$ & 6 & Price-elasticity of demand for a specific good variety \\
\hline$\tilde{\eta}$ & 21 & Wage-elasticity of demand for a specific labor variety \\
\hline$\alpha$ & 0.8 & Fraction of firms not setting prices optimally each quarter \\
\hline$\tilde{\alpha}$ & 0.69 & Fraction of labor markets not setting wages optimally each quarter \\
\hline$b$ & 0.69 & Degree of habit persistence \\
\hline$\phi_{1}$ & 0.0459 & Transaction cost parameter \\
\hline$\phi_{2}$ & 0.1257 & Transaction cost parameter \\
\hline$\phi_{3}$ & 1 & Preference parameter \\
\hline$\phi_{4}$ & 0.5301 & Preference parameter \\
\hline$\kappa$ & 2.79 & Parameter governing investment adjustment costs \\
\hline$\gamma 1$ & 0.0412 & Parameter of capacity-utilization cost function \\
\hline$\gamma 2$ & 0.0601 & Parameter of capacity-utilization cost function \\
\hline$\chi$ & 0 & Degree of price indexation \\
\hline$\tilde{\chi}$ & 1 & Degree of wage indexation \\
\hline$\mu_{\Upsilon}$ & 1.0042 & Quarterly growth rate of investment-specific technological change \\
\hline$\sigma_{\mu_{\Upsilon}}$ & 0.0031 & Std. dev. of the innovation to the investment-specific technology shock \\
\hline$\rho_{\mu_{\Upsilon}}$ & 0.20 & Serial correlation of the log of the investment-specific technology shock \\
\hline$\mu_{z}$ & 1.00213 & Quarterly growth rate of neutral technology shock \\
\hline$\sigma_{\mu_{z}}$ & 0.0007 & Std. dev. of the innovation to the neutral technology shock \\
\hline$\rho_{\mu_{z}}$ & 0.89 & Serial correlation of the log of the neutral technology shock \\
\hline $\bar{g}$ & 0.2141 & Steady-state value of government consumption (quarterly) \\
\hline$\sigma_{\epsilon^{g}}$ & 0.008 & Std. dev. of the innovation to log of gov. consumption \\
\hline$\rho_{g}$ & 0.9 & Serial correlation of the $\log$ of government spending \\
\hline
\end{tabular}


Figure 1: Degree of Price Stickiness and the Optimal Rate of Inflation

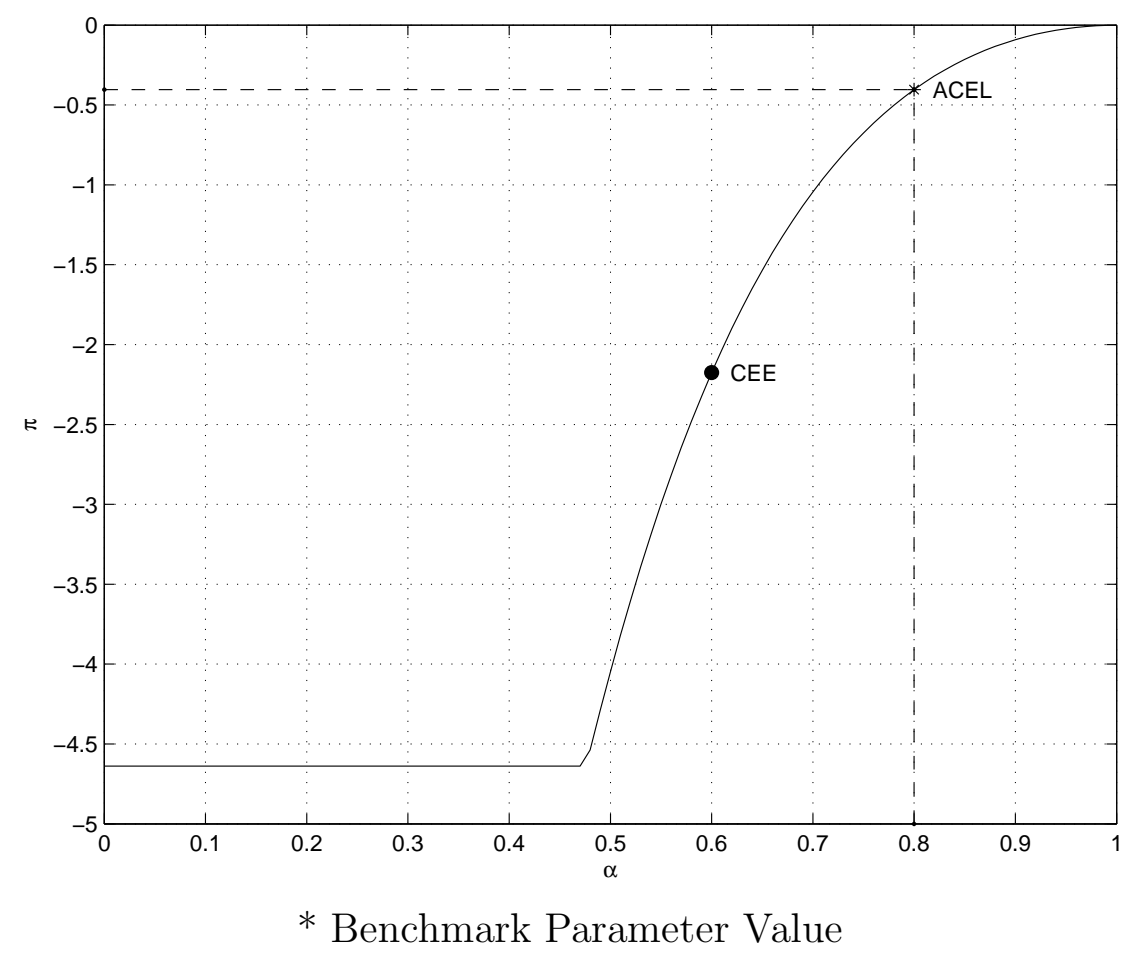

Note: CEE and ACEL indicate, respectively, the parameter values estimated by Christiano, Eichenbaum, and Evans (2005) and Altig et al. (2005). All parameters other than $\alpha$ take their baseline values, given in table 1.

identical to the present one, estimate an marginal-cost-gap coefficient in the Phillips curve that is consistent with a value of $\alpha$ of around 0.8 when the market for capital is assumed to be centralized, as is maintained in our formulation. ${ }^{4}$ Both CEE and ACEL use an impulseresponse matching technique to estimate $\alpha$. Bayesian estimates of this parameter include Del Negro et al. (2004) and Levin et al. (2005) who report posterior means of 0.67 and 0.83 , respectively, and 90-percent probability intervals of $(0.51,0.83)$ and $(0.81,0.86)$, respectively. Evidence on price stickiness based on microeconomic data suggest a much higher frequency of price changes than the evidence based on macro data. The findings reported in Bils and Klenow (2004) and Golosov and Lucas (2003), for example, suggest values of $\alpha$ of around $1 / 3$, or a degree of price stickiness of about 1.5 quarters.

Figure 1 displays the relationship between the degree of price stickiness, $\alpha$, and the optimal rate of inflation in percent per year, $\pi$. When $\alpha$ equals 0.5 , the lower range of the

\footnotetext{
${ }^{4}$ If, instead, capital accumulation is assumed to be firm-specific, then ACEL's estimate of the Phillips curve is consistent with a value of $\alpha$ of about 0.7 .
} 
available empirical evidence using macro data, the optimal rate of inflation is -4 percent, virtually equal to the level called for by the Friedman rule. For our baseline value of $\alpha$ of 0.8 , which is near the upper range of the available empirical evidence using macro data, the optimal level of inflation rises to -0.4 percent, which is close to price stability. Also evident from figure 1 is the fact that values of $\alpha$ based on microeconomic evidence, around $1 / 3$, imply that the Friedman rule is Ramsey optimal in the long-run.

The above analysis suggests that it is of outmost importance to devote further research into refining the available estimates of the degree of price stickiness. This research should aim not only at narrowing the range of values that stem from macro evidence but also at reconciling the apparent disconnect between estimates emerging from macro and micro data.

Besides the uncertainty surrounding the estimation of the degree of price stickiness, a second aspect of the apparent difficulty in establishing reliably the long-run level of inflation has to do with the shape of the relationship linking the degree of price stickiness to the optimal level of inflation. The problem resides in the fact that this relationship becomes significantly steep precisely for that range of values of $\alpha$ that is empirically most compelling. The problem would not arise if the steep portion of the relationship would take place at values of $\alpha$ below $1 / 3$ or above 0.8 , say. It turns out that an important factor determining the shape of the function relating the optimal level of inflation to the degree of price stickiness is the underlying fiscal policy regime.

\subsection{Fiscal Policy and the Optimal Inflation Rate}

In this paper, we follow the widespread practice in the literature on optimal monetary policy in the neo-Keynesian framework of ignoring fiscal considerations by implicitly or explicitly assuming the existence of lump-sum, nondistorting taxes that balance the government budget at all times and under all circumstances. This assumption is clearly unrealistic and usually maintained on the sole basis of simplicity. We wish to argue that taking explicitly into account the fiscal side of the optimal policy problem has crucial consequences for the optimal long-run level of inflation.

Fiscal considerations fundamentally change the long-run tradeoff between price stability and the Friedman rule. To see this, we now briefly consider an economy where lump-sum taxes are unavailable. Instead, the fiscal authority must finance government purchases by means of proportional capital and labor income taxes. The social planner sets jointly monetary and fiscal policy in a Ramsey-optimal fashion. The details of this environment are contained in Schmitt-Grohé and Uribe (2005a). Figure 2 displays the relationship between the degree of price stickiness, $\alpha$, and the optimal rate of inflation, $\pi$. The solid line cor- 
Figure 2: Price Stickiness, Fiscal Policy, and Optimal Inflation

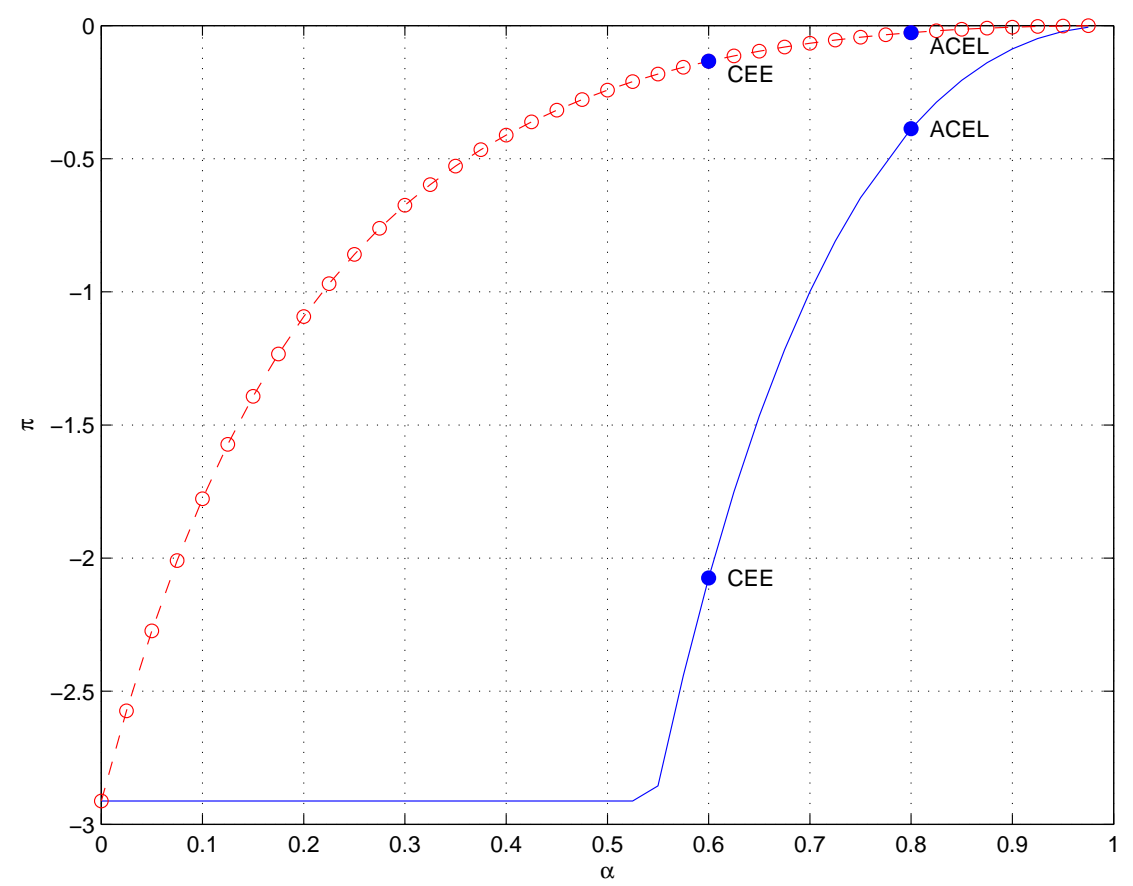

Lump-Sum Taxes $\quad$-o-o- Optimal Distortionary Taxes

Note: CEE and ACEL indicate, respectively, the values for the parameter $\alpha$ used by Christiano, Eichenbaum, and Evans (2005) and Altig et al. (2005). 
responds to the baseline case considered in this paper (featuring lump-sum taxes). ${ }^{5}$ The dash-circled line corresponds to the economy with optimally chosen income taxes analyzed in Schmitt-Grohé and Uribe (2005a). ${ }^{6}$ In stark contrast to what happens under lump-sum taxation, under optimal distortionary taxation the function linking $\pi$ and $\alpha$ is flat and very close to zero for the entire range of macro-data-based empirically plausible values of $\alpha$, namely 0.5 to 0.8 . In other words, when taxes are distortionary and optimally determined, price stability emerges as a prediction that is robust to the existing uncertainty about the exact degree of price stickiness. Even if one focuses on the evidence of price stickiness stemming from micro data, the model with distortionary Ramsey taxation predicts an optimal long-run level of inflation that is much closer to zero than to the level predicted by the Friedman rule.

Our intuition for why price stability arises as a robust policy recommendation in the economy with optimally set distortionary taxation runs as follows. Consider the economy with lump-sum taxation. Deviating from the Friedman rule (by raising the inflation rate) has the benefit of reducing the price dispersion that originates in the presence of price stickiness. Consider next the economy with Ramsey-optimal income taxation and no lump-sum taxes. In this economy, deviating from the Friedman rule still provides the benefit of reducing price dispersion. However, in this economy increasing inflation has the additional benefit of increasing seignorage revenue thereby allowing the social planner to lower distortionary income tax rates. Therefore, the Friedman-rule versus price-stability tradeoff is tilted in favor of price stability.

It follows from this intuition that what is essential in inducing the optimality of price stability is that on the margin the fiscal authority trades off the inflation tax for regular taxation. Indeed, it can be shown that if distortionary tax rates are fixed, even if they are fixed at the level that is optimal in a world without lump-sum taxes, and the fiscal authority has access to lump-sum taxes on the margin, the optimal rate of inflation is much closer to the Friedman rule than to zero. In this case, increasing inflation no longer has the benefit of reducing distortionary taxes. As a result, the Ramsey planner has less incentives to inflate.

\footnotetext{
${ }^{5}$ In producing the solid line shown in figure 2, all structural parameters take their baseline values shown in table 1 except for the long-run growth rates of the two productivity shocks, which are set to zero. This deviation from the baseline calibration is necessary to preserve comparability with the model in SchmittGrohé and Uribe (2005a), which features no long-run growth. The solid line looks essentially like the one shown in figure 1, with the only difference that at the Friedman rule the inflation rate is -2.9 percent, whereas in figure 1 it is -4.6 percent. This difference is explained by the lack of growth in the model used to produce the solid line in figure 2.

${ }^{6}$ In producing the dash-circled line shown in figure 2, we set all structural parameter values to those shown in table 1 in the present paper, except for those governing long-run growth, which are set to zero. The model economy features proportional labor, capital, and profit taxes. The profit tax rate is constrained to be equal to the capital income tax rate. Government transfers are set to zero.
} 
Figure 3: Degree of Price Indexation and the Optimal Rate of Inflation

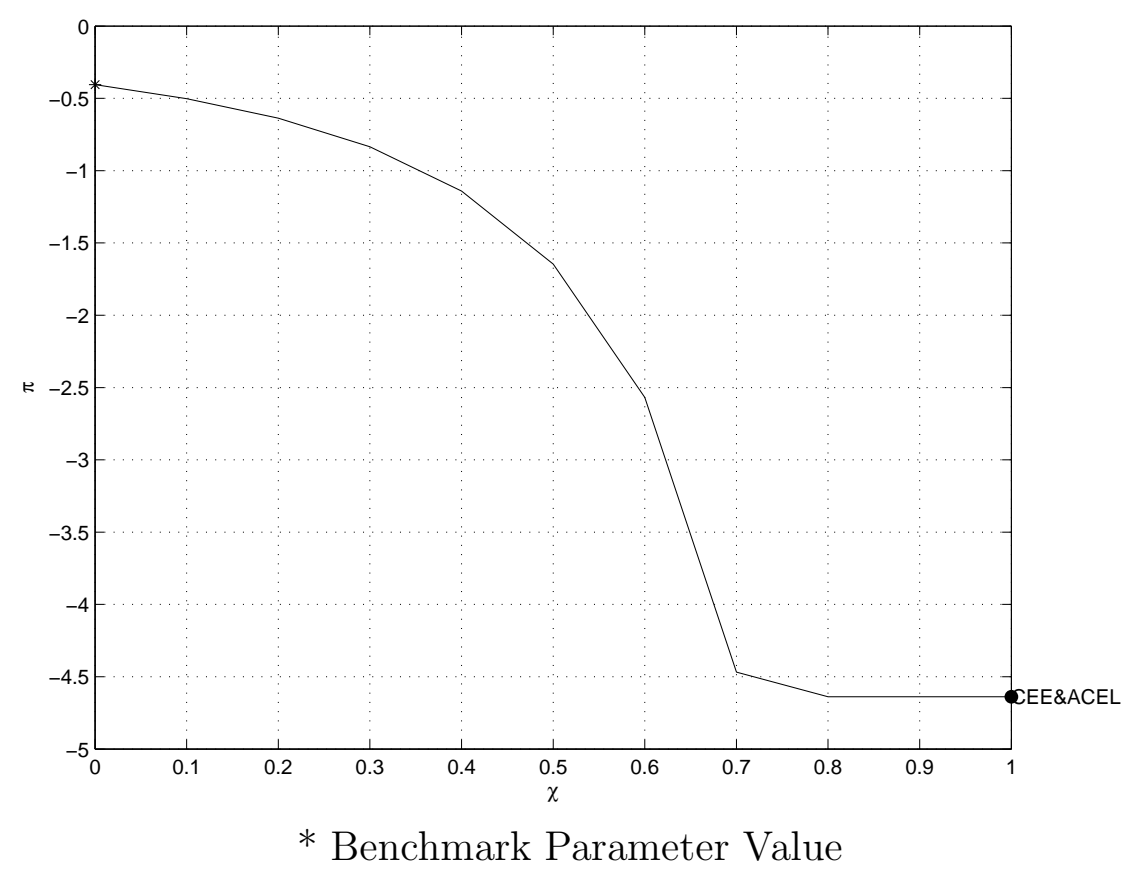

Note: CEE and ACEL indicate, respectively, the value of $\chi$ used by Christiano, Eichenbaum, and Evans (2005) and Altig et al. (2005). All parameters other than $\chi$ take their baseline values, given in table 1 .

\subsection{Price Indexation and the Optimal Inflation Rate}

The parameter $\chi$ measuring the degree of price indexation is crucial in determining the optimal level of long-run inflation. The reason is that when prices are fully indexed $(\chi=$ 1), price dispersion disappears in the deterministic steady state. As a result the social planner faces no longer a tradeoff between minimizing price dispersion and minimizing the opportunity cost of holding money. In such an environment, the Friedman rule is Ramsey optimal. In the absence of perfect indexation $(\chi<1)$, any deviation from zero inflation will entail price dispersion, and the lower the degree of indexation, the higher will be the price dispersion associated with a given level of inflation. Consequently, the Ramsey optimal deflation rate is increasing in the degree of price indexation.

Figure 3 shows that the Ramsey optimal inflation rate is indeed a decreasing function of the indexation parameter $\chi$. CEE and ACEL assume that prices are perfectly indexed to lagged inflation, that is, they calibrate the parameter $\chi$ to be unity. Under this assumption, the Friedman rule is optimal in the deterministic Ramsey steady state. However, the few 
Figure 4: Money Demand and the Optimal Rate of Inflation

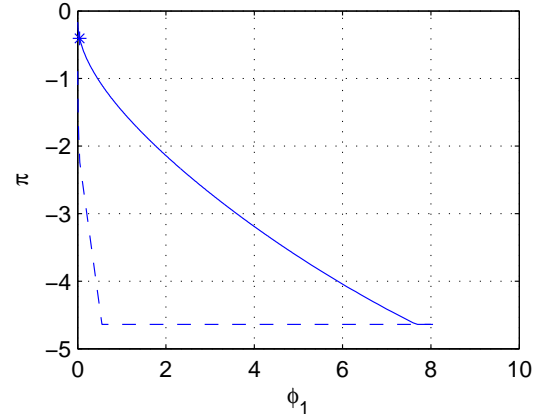

$\alpha=0.8$

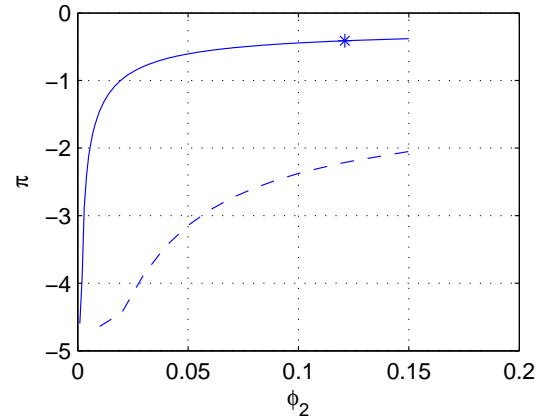

* Benchmark

Note: In each panel, all parameters other than the one shown take their baseline values, given in table 1 .

existing studies that attempt to estimate econometrically the indexation parameter $\chi$ find little empirical support for price indexation. For example, Levin et al. (2005) using Bayesian methods report a tight estimate of $\chi$ of 0.08. Similarly, Cogley and Sbordone (2005) using a different empirical strategy than Levin et al. also find virtually no evidence of price indexation in U.S. data. As we argued above, these two empirical studies motivate our setting $\chi=0$.

\subsection{Money Demand and the Optimal Inflation Rate}

Given the long-run policy tradeoffs present in the model - namely, minimizing the opportunity cost of holding money (by setting $R_{t}=1$ ) versus minimizing price dispersion (by setting $\pi_{t}=1$ ) - one should expect that the larger is the money demand friction, the closer is the optimal rate of inflation to the one prescribed by the Friedman rule. Figure 4 displays the optimal rate of inflation as a function of the two structural parameters defining the demand for money by households, $\phi_{1}$ and $\phi_{2}$. The figure suggests that the optimal rate of inflation is rather insensitive to changes in these two parameters. For instance, at the baseline value of 0.05 for the parameter $\phi_{1}$, the optimal rate of inflation is -0.4 percent per year and money demand is 17 percent of GDP. If one increases $\phi_{1}$ by a factor of 10 to 0.5 , the optimal rate of deflation is still small at only 1 percent, but the demand for money doubles to 35 percent of GDP. One must increase $\phi_{1}$ by a factor of more than 150 to around 8 to induce an optimal inflation rate close to the Friedman rule. At this value of $\phi_{1}$, the demand for money is larger than one entire annual GDP. 
The reason for the implied low sensitivity of the Ramsey inflation rate with respect to the parameters defining the demand for money is the assumed high degree of price stickiness. This distortion is so dominant in the present model that optimal policy is overwhelmingly geared toward price stability. As a result, low inflation survives as the overriding goal of monetary policy even for economically large values of the money demand distortion. If one lowers the degree of price stickiness, the optimal rate of inflation becomes much more sensitive with respect the transaction-cost parameter $\phi_{1}$. Figure 4 displays with a dashed line the relationship between the optimal rate of inflation and the parameters $\phi_{1}$ and $\phi_{2}$ when the sticky-price parameter $\alpha$ takes the value 0.6. In this case, the optimal rate of inflation falls from near price stability to the Friedman rule much faster as one increases $\phi_{1}$ than in the baseline case in which $\alpha$ is 0.8 .

A similar message emerges as one varies the other transaction cost parameter, $\phi_{2}$. Only for economically implausible values of $\phi_{2}$ (ones implying extremely high interest-rate elasticities of money demand) does the Friedman rule emerge as Ramsey optimal.

\subsection{Implications for Inflation Targeting}

A robust implication of the ACEL model studied here is that the central bank should target mild deflation. This implication is at odds with the observed inflation goals among the by-now large number of industrialized and emerging-market countries that self-identify their monetary policy as inflation targeting. In industrialized countries, inflation targets typically lie in the rage of 2 to 3 percent per year. Inflation targets are somewhat higher in developing countries.

It is therefore a challenge for monetary policy to square theoretically optimal inflation targets with actual ones. One reason often offered for why the inflation target should be positive is that too low an inflation target (in particular, zero or negative targets) would leave the central bank too close to the zero bound on nominal interest rates, thereby impairing the monetary authority's ability to steer the economy out of recession. Our analysis thus far is necessarily mute on this point because we have limited attention to a characterization of the Ramsey steady state. In order to ascertain whether the zero bound will indeed be frequently visited under the Ramsey optimal stabilization policy, a dynamic equilibrium analysis must be carried out. We turn to this matter next. 


\section{$5 \quad$ Ramsey Dynamics}

In this section, we characterize the business cycle dynamics that arise in the stochastic steady state of the Ramsey equilibrium. We approximate the Ramsey equilibrium dynamics by solving a first-order approximation to the Ramsey equilibrium conditions. There is evidence that first-order approximations to the Ramsey equilibrium conditions deliver dynamics that are fairly close to those associated with the exact solution. For instance, in Schmitt-Grohé and Uribe (2004b) we compute the exact solution to the Ramsey equilibrium in a flexible-price dynamic economy with money, income taxes, and monopolistic competition in product markets. In Schmitt-Grohé and Uribe (2004a) we compute the solution to the exact same economy using a first-order approximation to the Ramsey equilibrium conditions. We find that the exact solution is not significantly different from the one based on a first-order approximation. More recently, Benigno and Woodford (2005) have shown, in the context of optimal taxation in the standard RBC model, that the first-order approximation to the Ramsey equilibrium conditions implies second moments that are similar to the second moments computed from an approximation based on a minimum-weighted-residual method reported in Chari et al. (1995).

\subsection{Is the Zero Bound an Impediment to Optimal Policy?}

As mentioned earlier, one argument against setting a zero or negative inflation target, as recommended by the present model, is that at zero or negative rates of inflation the risk of hitting the zero lower bound on nominal interest rates would severely restrict the central bank's ability to conduct successful stabilization policy. This argument is made explicit in Summers (1991), for example. Table 2 reports the standard deviations of the nominal interest rate as well as other key macroeconomic variables under the Ramsey optimal stabilization policy. In computing these second moments, all structural parameters of the model take the values shown in table 1 . The table shows that the standard deviation of the nominal interest rate is only 0.4 percentage points at an annual rate. At the same time, the Ramsey steady-state level of the nominal interest rate is 4.4 percent. These two figures taken together imply that for the nominal interest rate to hit the zero bound, it must fall more than 10 standard deviations below its target level. The probability of this happening is so small that in the context of the estimated medium-scale model studied in this paper, the zero bound on nominal interest rates does not impose an economically important constraint on the conduct of optimal monetary policy.

This conclusion appears to be robust to changes in the degree of price or wage stickiness within the range of available empirical estimates for the parameters determining the degree 
Table 2: Ramsey Optimal Stabilization Policy: Second Moments

\begin{tabular}{|c|c|c|c|}
\hline$\overline{\text { Variable }}$ & $\begin{array}{c}\alpha=0.8 \\
\tilde{\alpha}=0.69\end{array}$ & $\begin{array}{l}\alpha=0.8 \\
\tilde{\alpha}=0.9\end{array}$ & $\begin{array}{c}\alpha=0.6 \\
\tilde{\alpha}=0.69\end{array}$ \\
\hline & \multicolumn{3}{|c|}{ Standard Deviation } \\
\hline Nominal Interest Rate & 0.4 & 0.4 & 0.3 \\
\hline Price Inflation & 0.1 & 0.4 & 0.2 \\
\hline Wage Inflation & 1.2 & 1.0 & 1.2 \\
\hline Output Growth & 0.8 & 0.8 & 0.8 \\
\hline Consumption Growth & 0.5 & 0.5 & 0.5 \\
\hline \multirow[t]{2}{*}{ Investment Growth } & 1.3 & 1.5 & 1.3 \\
\hline & \multicolumn{3}{|c|}{$\underline{\text { Serial Correlation }}$} \\
\hline Nominal Interest Rate & 0.9 & 0.8 & 0.9 \\
\hline Price Inflation & 0.8 & 0.9 & 0.8 \\
\hline Wage Inflation & 0.7 & 0.5 & 0.6 \\
\hline Output Growth & 0.4 & 0.5 & 0.5 \\
\hline Consumption Growth & 0.9 & 0.9 & 0.9 \\
\hline \multirow[t]{2}{*}{ Investment Growth } & 0.8 & 0.7 & 0.8 \\
\hline & \multicolumn{3}{|c|}{ Correlation with Output Growtl } \\
\hline Nominal Interest Rate & 0.4 & 0.0 & 0.3 \\
\hline Price Inflation & -0.3 & -0.5 & -0.4 \\
\hline Wage Inflation & 0.6 & 0.4 & 0.6 \\
\hline Output Growth & 1.0 & 1.0 & 1 \\
\hline Consumption Growth & 0.4 & 0.4 & 0.4 \\
\hline Investment Growth & 0.4 & 0.5 & 0.4 \\
\hline
\end{tabular}

The standard deviation is measured in percentage points per year. 
of nominal sluggishness (see columns 2 and 3 of table 2).

\subsection{Optimality of Inflation Stability}

The Ramsey authority faces a three-dimensional tradeoff in determining the optimal degree of inflation volatility. The sticky price distortion in isolation calls for minimizing inflation volatility. The money demand distortion, on the other hand, calls for stabilizing the opportunity cost of holding money, that is, minimizing the standard deviation of $R_{t}$. Finally, the sticky wage distortion renders stabilization of wage inflation (in the absence of indexation) or stabilization of wage inflation net of lagged price inflation (under full indexation to past price inflation) Ramsey optimal. Table 2 shows that this three-way tradeoff is resolved overwhelmingly in favor of inflation stability.

To see how sensitive the inflation stability goal is with respect to the size of the sticky wage distortion, we also consider the case of $\tilde{\alpha}=0.9$, which implies that unions reoptimize wages only every 10 quarters. In this case, as expected, the optimal volatility of price inflation increases and that of wage inflation falls. The optimal standard deviation of price inflation is now 0.4 percent per year and the optimal standard deviation of wage inflation is now 1.0 percent. Yet, price inflation continues to be significant smoother over the business cycle than wage inflation. We conclude that a central characteristic of optimal stabilization policy is smooth inflation rates. In this sense, one could say that the Ramsey planner pursues a policy of inflation targeting.

\subsection{Ramsey Optimal Impulse Responses and Variance Decompo- sition}

Optimal stabilization policy will in general be shaped by the number and nature of the exogenous shocks generating aggregate fluctuations. There is considerable debate in the empirical literature about the identification of the main sources of business cycle fluctuations. One branch of the literature uses structural vector autoregression analysis to identify specific structural shocks. Examples of this approach are Altig et al. (2005) and Fisher (2005). The work of Fisher (2005) suggests that investment specific technology shocks may explain as much as 50 percent of variations in hours worked. Altig et al. identify monetary policy shocks and investment-specific as well as neutral technology shocks. They find that investmentspecific shocks play a smaller role in generating business cycles: specifically, they estimate that neutral and investment-specific technology shocks together explain only about one third of the fluctuations in hours, output, and consumption. 
Table 3: Percent of variance explained by each of the three exogenous disturbances in the Ramsey equilibrium

\begin{tabular}{llll}
\hline \hline Variable & $\mu_{\Upsilon, t}$ & $\mu_{z, t}$ & $g_{t}$ \\
\hline $\ln y_{t} / y_{t-1}$ & 0.11 & 0.44 & 0.45 \\
$\ln c_{t} / c_{t-1}$ & 0.10 & 0.80 & 0.10 \\
$\ln I_{t} / I_{t-1}$ & 0.61 & 0.33 & 0.06 \\
$\ln R_{t}$ & 0.21 & 0.62 & 0.17 \\
$\ln \pi_{t}$ & 0.13 & 0.83 & 0.04 \\
$\ln \pi_{t}^{W}$ & 0.37 & 0.63 & 0.00 \\
$\ln h_{t}^{d}$ & 0.47 & 0.44 & 0.09 \\
\hline \hline
\end{tabular}

On the other hand, there is a very active recent literature that uses Bayesian methods to estimate the entire data generating process of a dynamic stochastic general equilibrium model. The paper of Smets and Wouters (2004) is a key example of this line of research. Those authors estimate a model with 10 shocks. One might consider using all of those 10 estimated shocks in the optimal policy problem. However, in econometrically estimated versions of the model studied in this paper (or variations thereof), it is often the case that many of these shocks are difficult to interpret economically. In effect, these shocks, to a large extent, represent simple econometric residuals reflecting the distance between model and data rather than true sources of business-cycle fluctuations. A case in point are shocks to Euler equations or markup shocks. Before incorporating this type of residual as driving forces, it is perhaps more productive to give theory a chance to get closer to the data. Therefore, we do not attempt to build a model that includes all sources of fluctuations. We simply focus on three shocks that have been shown in the empirical literature to explain a significant fraction of aggregate fluctuations. Namely, neutral and investment-specific technology shocks and government purchases shocks.

Table 3 shows how important each of these three shocks is in explaining short-run fluctuations under the Ramsey regime. Variations in output growth are explained in equal parts by government purchases shocks and neutral technology shocks, which each account for 45 percent of output growth variance. Investment-specific productivity shocks play a minor role in driving fluctuations in output growth. However, investment-specific shocks are important in explaining movements in hours worked (47 percent), wage inflation (37 percent), and investment growth (61 percent). Fluctuations in consumption growth, the nominal interest rate, inflation, and wage inflation are mainly driven by neutral productivity shocks with a small contribution of government purchases shocks.

Figure 5 shows the model's response to a one percentage increase in the growth rate 
Figure 5: Ramsey Response To A Neutral Productivity Shock
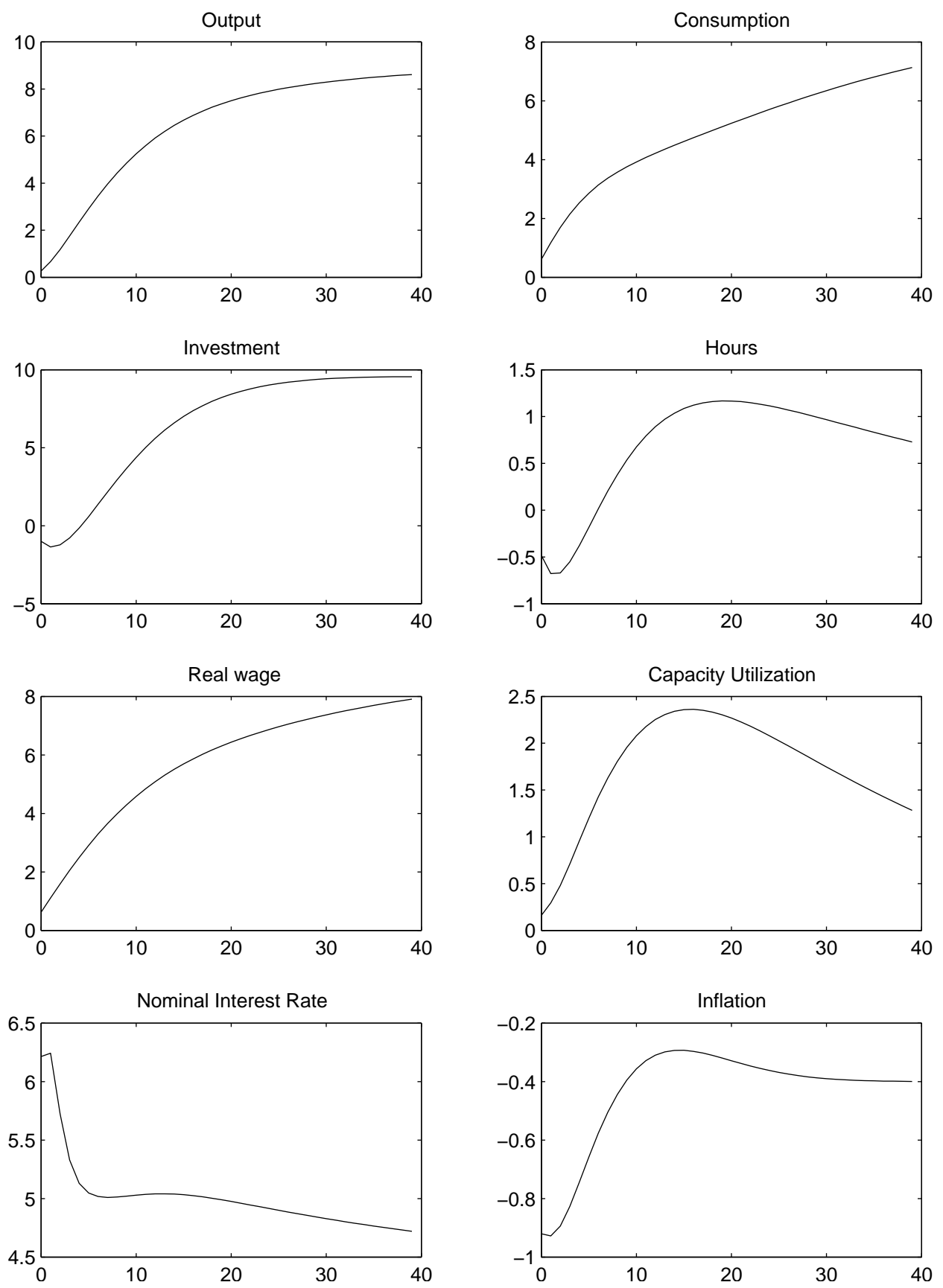

Note: The size of the initial innovation to the neutral technology shock is one percent, $\ln \left(\mu_{z, 0} / \mu_{z}\right)=1 \%$. The nominal interest rate and the inflation rate are expressed in levels in percent per year. Output, wages, investment, and consumption are expressed in cumulative growth rates in percent. Hours and capacity utilization are expressed in percentage deviations from their respective steady-state values. 
of the neutral technology shock $\left(\ln \left(\mu_{z, 0} / \mu_{z}\right)=1 \%\right)$. The Ramsey planner raises nominal interest rates by 175 basis points on impact and allows inflation to fall slightly by 45 basis points. This monetary tightening is short lived however, after 6 quarters the nominal interest rate is back at 5 percent, or 50 basis points above its long run target. We conjecture that the reason for this tightening is as follows. The Ramsey planner aims to replicate the real allocation associated with the flexible-price flexible-wage economy. In such an economy, the real interest rate would rise at least temporarily in response to a positive shock to the growth rate of technology. With sluggish nominal price adjustment, the Ramsey planner would like to induce a rise in the real interest rate without relying in costly movements in the inflation rate. Because the real interest rate equals the risk free nominal interest rate minus the inflation rate, it follows that the Ramsey-optimal policy is to raise nominal interest rates roughly by the amount that real interest rates would rise in the flexible-price economy. Interestingly, nominal interest rates are tightened not to avoid inflation, but rather to avoid deflation.

Currently, there exists an active debate surrounding the estimated effects of neutral technology shocks on hours. For example, Galí (1999) finds that hours decline on impact whereas ACEL find that hours increase. Consistent with the findings of Galí, our model predicts that under the Ramsey policy hours decline on impact in response to a positive innovation in the neutral technology shock. Our intuition for the initial decline in hours is as follows. Because monetary policy induces a sharp increase in real interest rates on impact, the wealth effect on consumption is muted initially. Additionally, due to the presence of adjustment costs in investment, investment spending does not increase much on impact. As a result the positive wealth effect generated by the increase in productivity growth materializes in an expansion of the consumption of leisure.

Figure 6 presents the Ramsey impulse responses to a one percent innovation in government purchases. A one percent increase in government consumption raises output by 0.15 percent. Given that in the model the share of public consumption in GDP is assumed to be 17 percent, it follows that the government spending multiplier implied by the model is slightly below unity. The model predicts that the government should increase interest rates in response to a positive government spending shock, which is in line with conventional wisdom.

Figure 7 displays the model's response to a one percentage point increase in the growth rate of investment-specific technological change. Ramsey policy calls for an easing of money market conditions in response to a positive investment-specific productivity shock. Again, our intuition is that the Ramsey planner tries to mimic the flexible-price equilibrium. In the absence of price stickiness, real interest rates would fall. Hence, the Ramsey planner 
Figure 6: Ramsey Response To a Government Purchases Shock
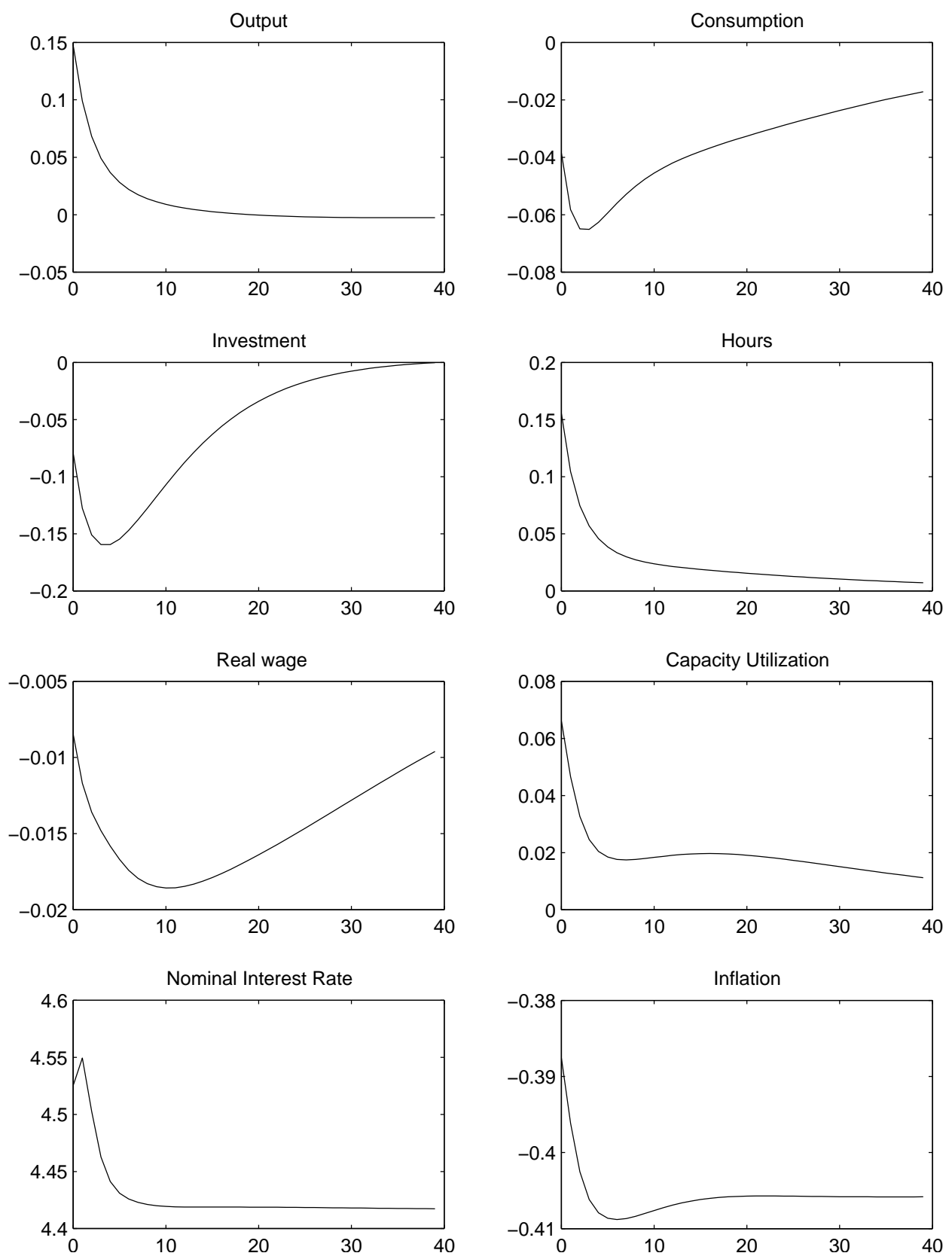

Note: The size of the initial innovation to government purchases is one percent of its steady state value, $\ln \left(\bar{g}_{0} / \bar{g}\right)=1 \%$. The nominal interest rate and the inflation rate are expressed in levels in percent at an annual rate. Output, wages, investment, and consumption are expressed in cumulative growth rates in percent. Hours and capacity utilization are expressed in percentage deviations from their respective steady-state values. 
Figure 7: Ramsey Response To An Investment-Specific Productivity Shock
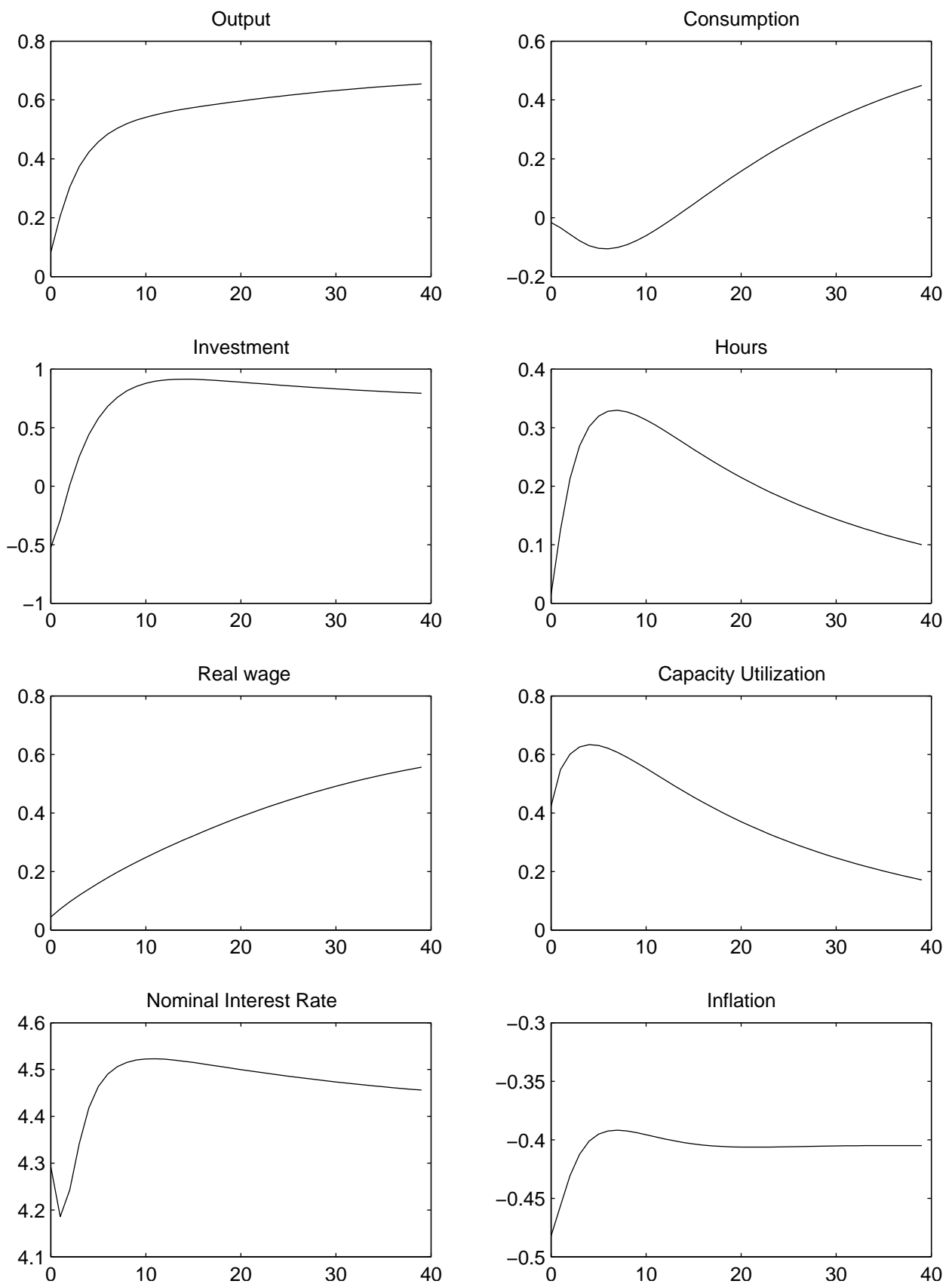

Note: The size of the initial innovation to the neutral technology shock is one standard deviation, $\ln \left(\mu_{\Upsilon, 0} / \mu_{\Upsilon}\right)=1 \%$. The nominal interest rate and the inflation rate are expressed in levels in percent per year. Output, wages, investment, and consumption are expressed in cumulative growth rates in percent. Hours and capacity utilization are expressed in percentage deviations from their respective steady-state values. 
lowers nominal rates so as to achieve a fall in real rates without putting upward pressure on inflation.

\section{Optimal Operational Interest-Rate Rules}

Ramsey outcomes are mute on the issue of what policy regimes can implement them. The information on policy one can extract from the solution to the Ramsey problem is limited to the equilibrium behavior of policy variables such as the nominal interest rate. But this information is in general of little use for central banks seeking to implement the Ramsey equilibrium. Specifically, the equilibrium process of policy variables in the Ramsey equilibrium is a function of all of the states of the Ramsey equilibrium. These state variables include all of the exogenous driving forces and all of the endogenous predetermined variables. Among this second set of variables are past values of the Lagrange multipliers associated with the constraints of the Ramsey problem. Even if the policymaker could observe the state of all of these variables, using the equilibrium process of the policy variables to define a policy regime would not guarantee the Ramsey outcome as the competitive equilibrium. The problem is that such a policy regime could give rise to multiple equilibria.

In this section, we show that a simple interest-rate feedback rule implements the Ramsey equilibrium in the medium-scale model under study. Specifically, we focus on finding parameterizations of interest-rate rules that satisfy the following 4 conditions: (a) They are simple, in the sense that they involve only a few observable macroeconomic variables; (b) They guarantee local uniqueness of the rational expectations equilibrium; (c) The associated path of the nominal interest rate does not violate the zero bound. ${ }^{7}$ and (d) They maximize the expected lifetime utility of the representative household conditional on the initial state of the economy being the deterministic steady state of the Ramsey economy. We refer to rules that satisfy criteria (a)-(c) as operational. We refer to operational rules that satisfy criterion (d) as optimal operational rules.

The family of rules that we consider consists of interest-rules whereby the nominal interest rate depends linearly on its own lag, the rates of price and wage inflation, and the growth rate of output. Formally, the interest-rate rule is given by

$$
\ln \left(\frac{R_{t}}{R^{*}}\right)=\alpha_{\pi} \ln \left(\frac{\pi_{t}}{\pi^{*}}\right)+\alpha_{W} \ln \left(\frac{\pi_{t}^{W}}{\pi^{W^{*}}}\right)+\alpha_{y} \ln \left(\frac{y_{t}}{y_{t-1} \mu_{y}^{*}}\right)+\alpha_{R} \ln \left(\frac{R_{t-1}}{R^{*}}\right) .
$$

The target values $R^{*}, \pi^{*}, \pi^{W^{*}}$ and $\mu_{y}^{*}$ are assumed to be the Ramsey steady-state values

\footnotetext{
${ }^{7}$ We approximate this constraint by requiring that in the competitive equilibrium two standard deviations of the nominal interest rate be less than the steady-state level of the nominal interest rate.
} 
of their associated endogenous variables. (The steady-state growth of output is indeed exogenous and given by $\mu_{z^{*}}$.) The variable $\pi_{t}^{W}$ denotes nominal wage inflation and in the nonstochachstic steady state we have that $\pi^{W^{*}} \equiv \mu_{z^{*}} \pi^{*}$. It follows that in our search for the optimal operational policy rule, we pick the four policy parameters $\left(\alpha_{\pi}, \alpha_{W}, \alpha_{y}, \alpha_{R}\right)$ so as to maximize welfare, $V_{t} \equiv E_{0} \sum_{t=0}^{\infty} \beta^{t} U\left(c_{t}-b c_{t-1}, h_{t}\right)$, where expectations are taken conditional on the initial state being the non-stochastic steady state of the Ramsey equilibrium. Given the complexity of the model, an exact numerical solution does not exist. We therefore approximate our conditional welfare measure to second-order accuracy using the numerical method developed in Schmitt-Grohé and Uribe (2004c).

\subsection{The Optimal Operational Rule}

We find that the optimal operational interest rate is given by

$$
\ln \left(\frac{R_{t}}{R^{*}}\right)=5.0 \ln \left(\frac{\pi_{t}}{\pi^{*}}\right)+1.6 \ln \left(\frac{\pi_{t}^{W}}{\pi^{W^{*}}}\right)-0.1 \ln \left(\frac{y_{t}}{y_{t-1} \mu_{y}^{*}}\right)+0.4 \ln \left(\frac{R_{t-1}}{R^{*}}\right)
$$

The optimal operational interest-rate rule is active in both price and wage inflation because both coefficients are greater than unity. In addition, the rule prescribes virtually no response to output growth. In this sense the optimized interest-rate rule can indeed be interpreted as a pure inflation targeting rule. According to the above rule, the policymaker reacts positively to lagged nominal interest rates. Because the interest-rate coefficient is less than unity, the rule is inertial but not superinertial. Thus, the policymaker is backward looking in its response to inflation deviations from target.

To quantify the difference in the level of welfare under the Ramsey policy and under the optimal operational rule, we compute the welfare costs of the optimal operational interestrate rules relative to the time-invariant equilibrium process associated with the Ramsey policy.

We assume that at time zero all state variables of the economy equal their respective Ramsey-steady-state values. Because the non-stochastic steady state is the same across all policy regimes we consider, computing expected welfare conditional on the initial state being the nonstochastic steady state ensures that the economy begins from the same initial point under all possible polices.

Consider the Ramsey policy, and denote the contingent plans for consumption and hours under the Ramsey policy by $c_{t}^{r}$ and $h_{t}^{r}$. Similarly, denote the contingent plans under the alternative policy regime by $c_{t}^{a}$ and $h_{t}^{a}$. Let $\lambda^{c}$ denote the welfare cost of adopting policy regime $a$ instead of the Ramsey policy conditional on a particular state in period zero. We 
Table 4: Welfare Under the Optimal Operational Rules

\begin{tabular}{|c|c|c|c|c|c|c|c|c|}
\hline Parameterization & $\alpha_{\pi}$ & $\alpha_{W}$ & $\alpha_{y}$ & $\alpha_{R}$ & $\left(100 \times \lambda^{c}\right)$ & $\left(100 \times \lambda^{u}\right)$ & $c_{2006} \lambda^{c}$ & $c_{2006} \lambda^{u}$ \\
\hline \multicolumn{9}{|l|}{ Optimized Rules [Eq. (48)] } \\
\hline Baseline Calibration & 5.0 & 1.6 & -0.1 & 0.4 & 0.001 & 0.001 & $\$ 0.23$ & $\$ 0.19$ \\
\hline High Wage Stickiness $(\tilde{\alpha}=0.9)$ & 0.4 & 1.9 & 0.1 & 2.3 & 0.008 & 0.005 & $\$ 2.50$ & $\$ 1.41$ \\
\hline \multicolumn{9}{|l|}{ Ad-Hoc Rule } \\
\hline Taylor Rule - Output Level & 1.5 & 0 & 0.5 & 0 & 0.14 & 0.16 & $\$ 41.81$ & $\$ 48.06$ \\
\hline
\end{tabular}

Note. The variable $c_{2006} \equiv \$ 30,441$ denotes nominal U.S. per capita personal consumption expenditures seasonally adjusted at annual rates, in the first quarter of 2006. Source: www.bea.gov.

define $\lambda^{c}$ as the fraction of regime $r$ 's consumption process that a household would be willing to give up to be as well off under regime $a$ as under regime $r$. It follows that $\lambda^{c}$ is implicitly defined by ${ }^{8}$

$$
\left.E_{0} \sum_{t=0}^{\infty} \beta^{t} U\left(c_{t}^{a}-b c_{t-1}^{a}\right), h_{t}^{a}\right)=E_{0} \sum_{t=0}^{\infty} \beta^{t} U\left(\left(1-\lambda^{c}\right)\left(c_{t}^{r}-b c_{t-1}^{r}\right), h_{t}^{r}\right)
$$

Similarly, one can derive an unconditional welfare cost measure. That is one can ask which fraction of consumption under the Ramsey policy are agents willing to give up, to attain the same unconditional expectation of lifetime utility as under the alternative policy. Let $\lambda^{u}$ denote this unconditional welfare cost measure. Then $\lambda^{u}$ is implicitly given by

$$
\left.E\left\{\sum_{t=0}^{\infty} \beta^{t} U\left(c_{t}^{a}-b c_{t-1}^{a}\right), h_{t}^{a}\right)\right\}=E\left\{\sum_{t=0}^{\infty} \beta^{t} U\left(\left(1-\lambda^{c}\right)\left(c_{t}^{r}-b c_{t-1}^{r}\right), h_{t}^{r}\right)\right\} .
$$

We restrict attention to approximations of $\lambda^{c}$ and $\lambda^{u}$ that are accurate up to second order. See the appendix for a derivation.

Table 4, displays the central result of this section. Namely, that the welfare costs of following the optimal operational interest rate rule rather than the Ramsey policy are virtually zero; agents are willing to give up less than one one-hundreths of one percent of the Ramsey consumption stream (or less than 23 cents per annum) to be as well off under the optimal

\footnotetext{
${ }^{8}$ Note that for analytical convenience we apply the factor $\left(1-\lambda^{c}\right)$ to $c_{-1}$ eventhough this variable is predetermined at the time of the policy evaluation. In Schmitt-Grohé and Uribe (2004d) we show that if one were not to apply the factor $\left(1-\lambda^{c}\right)$ to $c_{-1}$, then one would obtain a welfare cost measure that is slightly smaller than the one we obtain here. However, because the alternative welfare cost measure is proportioal to the one we use here, the welfare rankings would be unchanged. Furthermore, our conclusion that the opotimal operational rule yields virtually the same level of welfare as the Ramsey policy would only be strengthened.
} 
operational rule as under the Ramsey policy.

A central characteristic of the optimal rule is that its response to output is mute. Forcing the output coefficient, $\alpha_{y}$, to be zero, increases the welfare cost by less than one cent per year. This finding has an important policy implication. Central banks need not respond to a measure of output in order to implement an equilibrium that provides virtually the same level of welfare as the Ramsey policy.

While it is true that responding to output has virtually zero welfare gains, one can show that it may have significant welfare costs. In table 4 we consider a Taylor rule with a coefficient of 0.5 on deviations of output from trend $\left(\ln \left(Y_{t} / Y\right)\right)$ and an inflation coefficient of 1.5. This rule is associated with welfare costs of almost $\$ 50$ per person per year, or $\$ 200$ per 4-person household per year.

Interest-rate smoothing is not essential from a welfare point of view in the present economy. Under the optimal rule the interest rate smoothing coefficient is 0.4 . If one eliminates interest-rate smoothing by setting $\alpha_{R}=0$ while keeping the other rule coefficients at $\alpha_{\pi}=5$, $\alpha_{y}=0$, and $\alpha_{\pi^{W}}=1.6$, the welfare costs of the rule increase by 3 cents per year to 26 cents per year, which we regard as negligible. ${ }^{9}$

Next, we address the question of how important it is for the central bank to respond to both wage and price inflation rather than to just price inflation. Setting $\alpha_{\pi^{W}}=\alpha_{y}=\alpha_{R}=0$ and leaving $\alpha_{\pi}$ at the optimized value of 5 increases welfre costs to 81 cents per year per person (or 0.003 percent of annual consumption). This is still a fairly small number, which leads us to conclude that a simple policy prescription, namely, responding aggressively to price inflation only, can bring about an equilibrium in which agents are virtually as well off as under the Ramsey policy. In this sense, we can interpret our findings as supportive of inflation targeting policies.

Table 4 presents the optimal operational rule when wages are reoptimized every 10 quarters, or $\tilde{\alpha}=0.9$. In the baseline calibration, we draw from the work of Altig et al. (2005) and assume that wage contracts are reoptimized about every third quarter $(\tilde{\alpha}=0.69)$. As mentioned earlier, the model of Altig et al. (2005) adopts the Erceg et al. (2000) model of nominal wage stickiness. Under this formulation, wage dispersion generates heterogeneity in work intensity across households. In our formulation, all households supply the same amount of labor. In equilibrium, these two alternative modeling strategies result, up to first order, in a different labor markup coefficient in the wage Phillips curve. Specifically, under the assumption of no growth, $\mu_{v}=\mu_{z}=1$, the log-linear approximation to the wage inflation

\footnotetext{
${ }^{9}$ In Schmitt-Grohe and Uribe (2006) we study a simpler model without nominal wage rigidity or growth. In that model we also find that the optimal interest-rate rule delivers virtually the same level of welfare as the Ramsey policy, that the optimal response to output is nil, that responding to output can entail significant welfare costs, and that the welfare gains from interest-rate smoothing are negligible.
} 
Phillips curve in the Altig et al. model can be written as $\hat{\pi}_{t}^{W}-\hat{\pi}_{t-1}=\beta\left(E_{t} \hat{\pi}_{t+1}^{W}-\hat{\pi}_{t}\right)-\gamma \hat{\tilde{\mu}}_{t}$, where $\gamma=\frac{1}{1+\tilde{\eta}} \frac{(1-\tilde{\alpha})(1-\beta \tilde{\alpha})}{\tilde{\alpha}}$. In our model, under the assumption of full wage indexation, $\tilde{\chi}=1$ (as maintained in Altig et al., 2005, as well as in our baseline calibration), the wage Phillips-curve is given by $\hat{\pi}_{t}^{W}-\hat{\pi}_{t-1}=\beta\left(E_{t} \hat{\pi}_{t+1}^{W}-\hat{\pi}_{t}\right)-(1+\tilde{\eta}) \gamma \hat{\tilde{\mu}}_{t}$. This means that the coefficient on the labor market markup is different in the two models by a factor $(1+\tilde{\eta})$. Given the estimated value for $\gamma$ reported by Altig et al. and given our baseline values for $\tilde{\eta}$ and $\beta$ of 21 and $1.03^{-0.25}$, respectively, the implied value of $\tilde{\alpha}$ in the context of our model is about 0.9. With this degree of wage stickiness the optimized interest-rate rule calls for a more aggressive response to wage inflation and a less aggressive response to price inflation. In addition, the optimal rule now displays a superinertial response to lagged interest rates. The rule continues to call for a mute response to output variations. The welfare differences between the optimal operation rule and the Ramsey policy are still small at 0.005 percent of the Ramsey consumption stream.

In computing the coeffcients of the optimized policy rule, thus far we have restricted attention to maximizing lifetime utility of the representative household conditional on a particular initial the initial state of the economy being the nonstochastic Ramsey steady state. Alternative, one could pick policy-rule coefficients so as to maximize an unconditional measure of lifetime utility. Our results are robust to adopting this alternative. Specifically, under the unconditional welfare objective we obtain $\alpha_{\pi}=5.1, \alpha_{W}=1.6, \alpha_{y}=-0.1$, $\alpha_{R}=0.4,100 \times \lambda^{c}=0.001$, and $100 \times \lambda^{u}=0.001$.

Figures 8, 9, and 10 compare the impulse responses of all variables of the model to the three shocks driving aggregate fluctuations under the Ramsey-optimal policy (solid lines) and under the optimized operational interest-rate rule (broken lines). In the figures, inflation and the nominal interest rate are in percent per quarter deviations from their steady-state values. All other variables are expressed in percent deviations from their deterministic steady state. As described earlier in section 2.6 variables in capital letters are stationarity-inducing transformations of the corresponding variables in lowercase letters. The figures suggest a remarkable match between the Ramsey responses and the impulse responses associated with the optimized operational interest-rate rule.

\subsection{Interest-Rate Rules and Equilibrium Determinacy}

For an interest-rate feedback rule to be operational, we require that it induce a locally determinate rational expectations equilibrium. A natural question is what restrictions this requirement imposes on the values that the parameters defining the interest rate rule can take. Figure 11 displays with dots the values of the price- and wage-inflation coefficients 
Figure 8: Ramsey And Optimized Responses To An Investment-Specific Productivity Shock
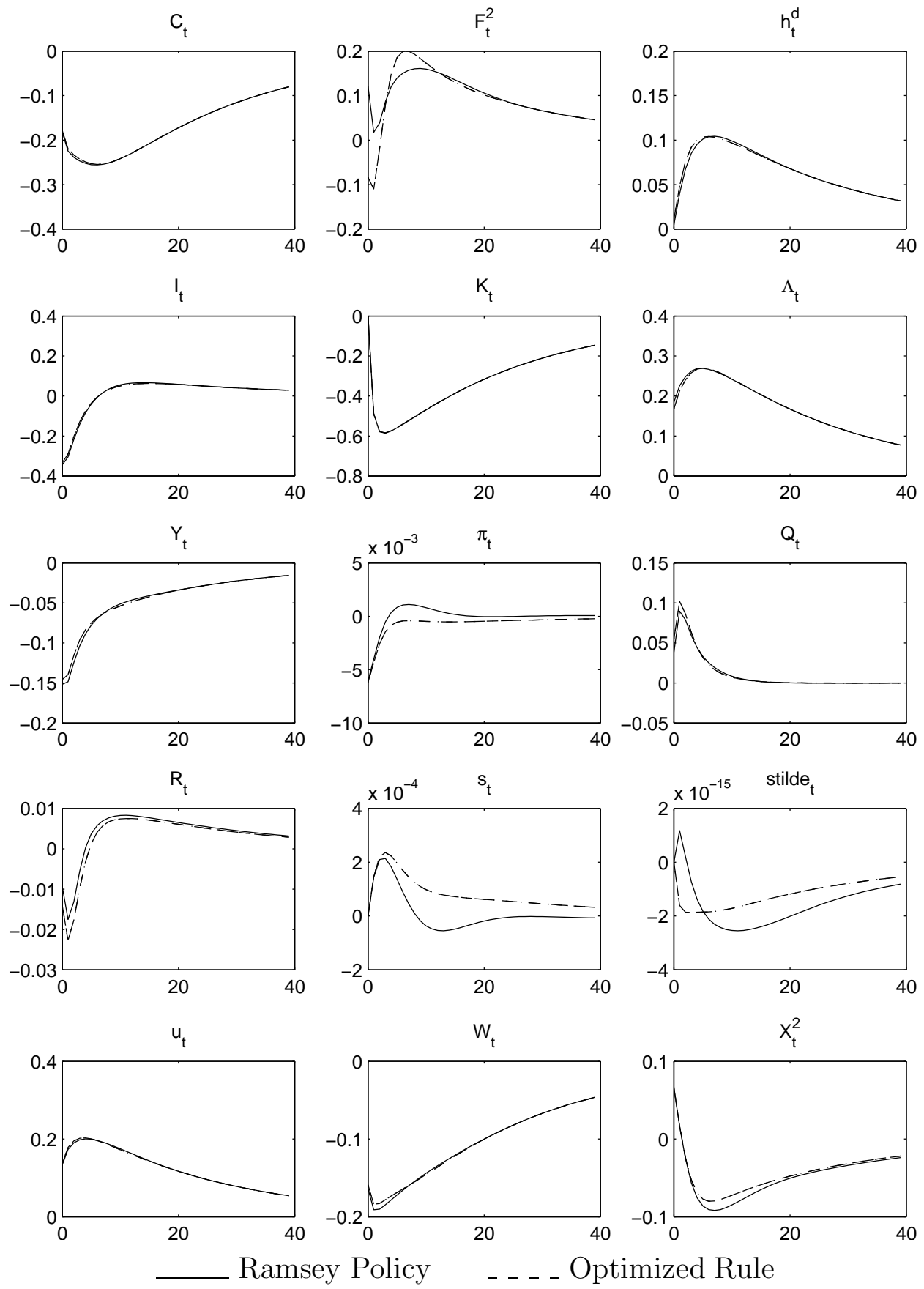
Figure 9: Ramsey And Optimized Responses To A Neutral Productivity Shock
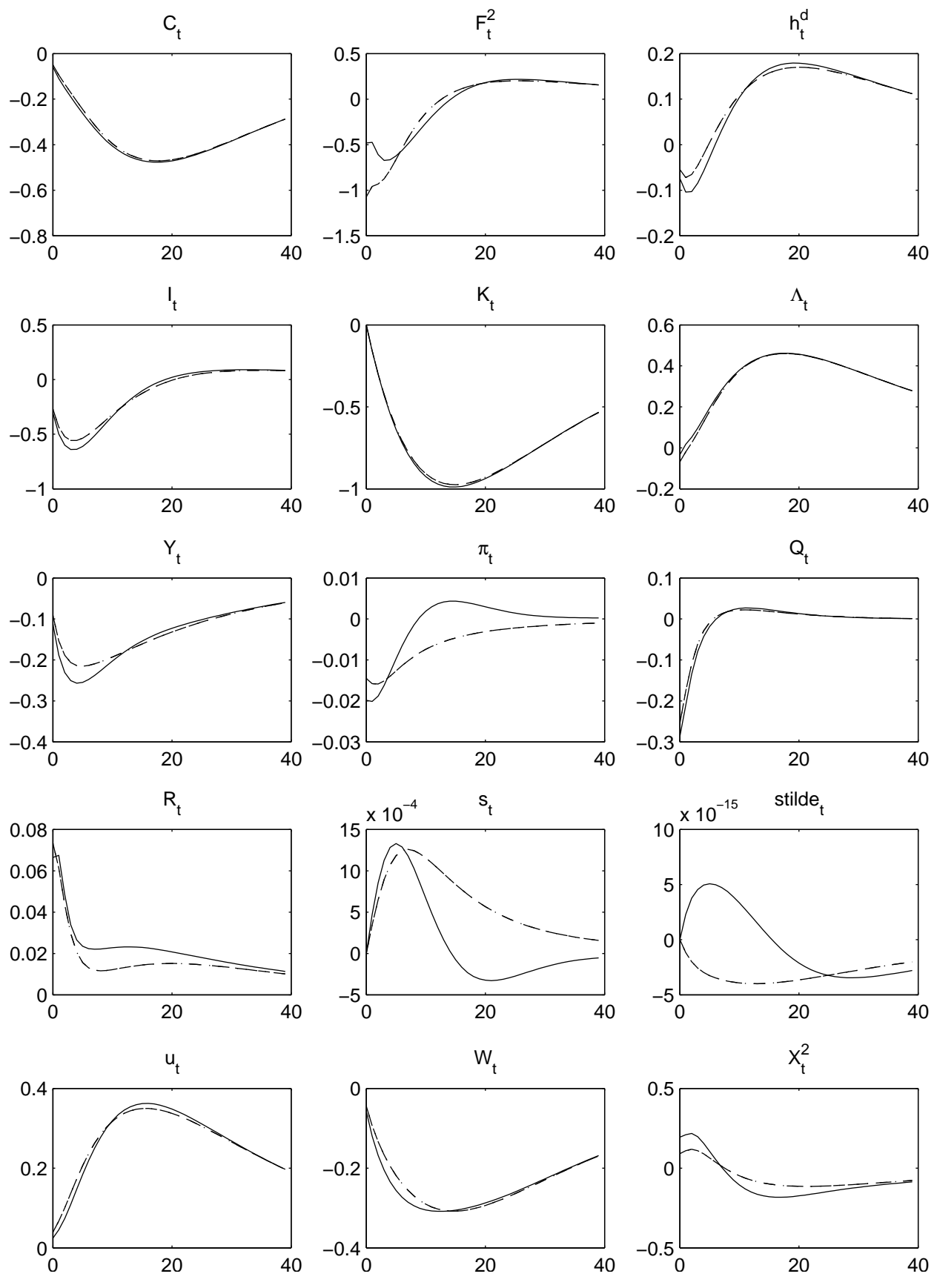

Ramsey Policy _ _ _ _ Optimized Rule 
Figure 10: Ramsey And Optimized Responses To A Government Purchases Shock
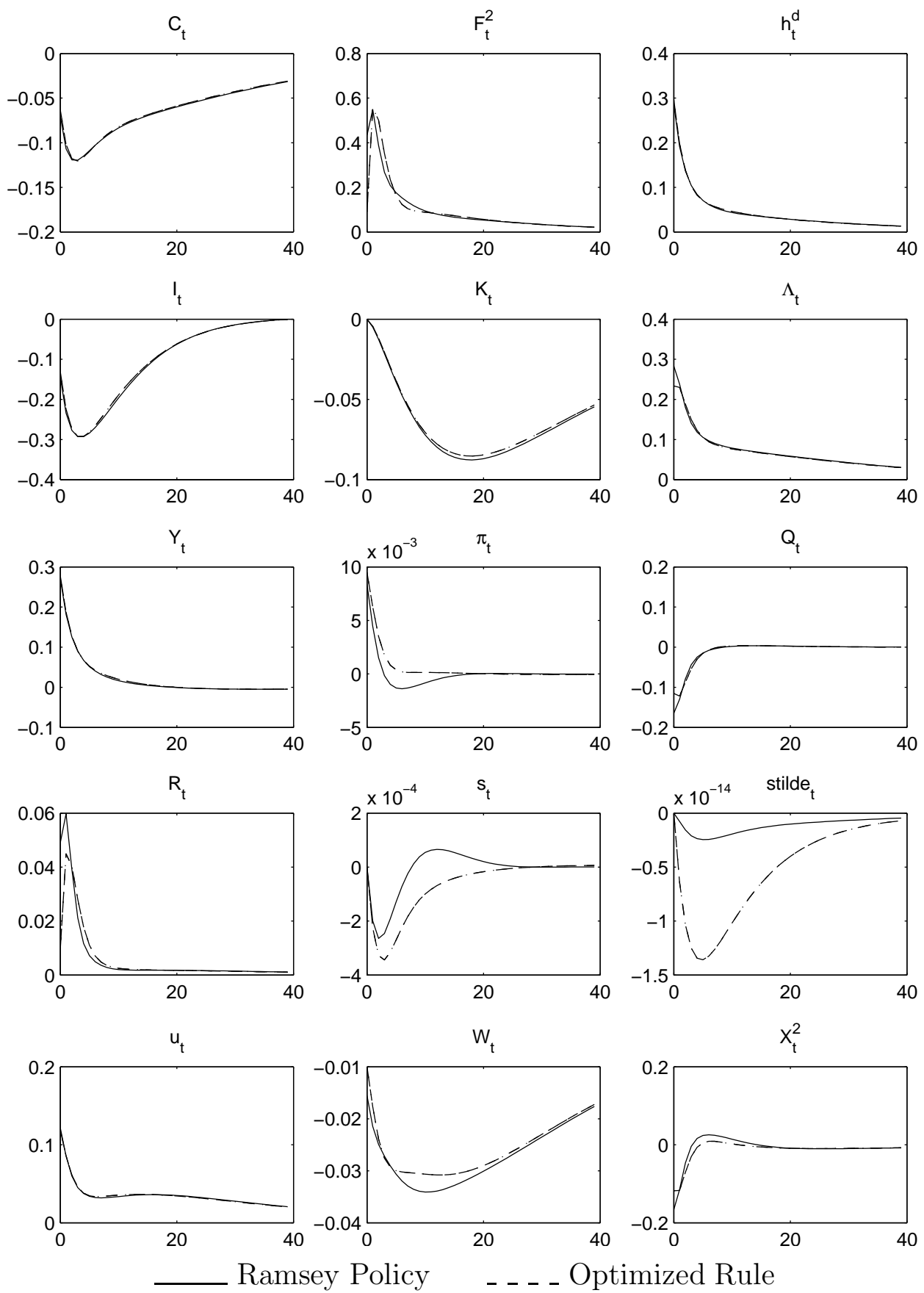
Figure 11: Interest-Rate Feedback Rules and Equilibrium Determinacy

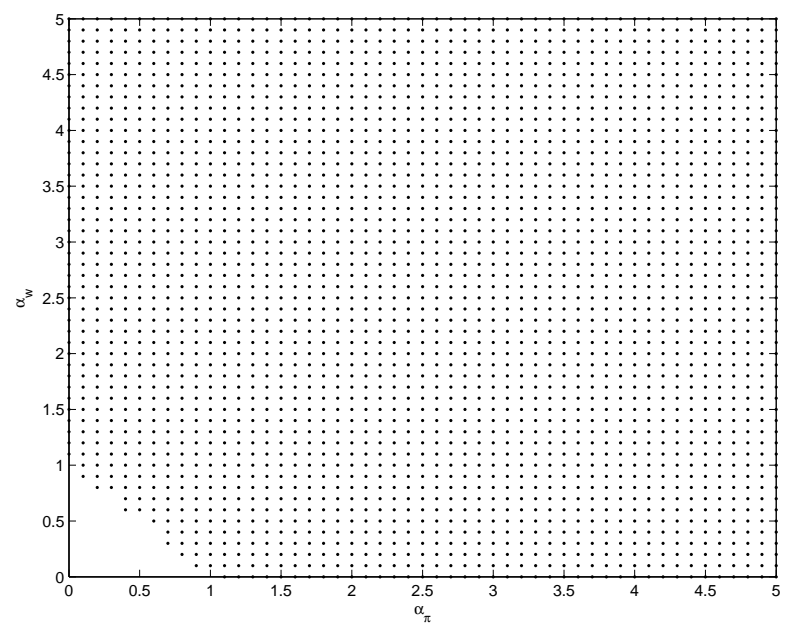

- Locally Determinate Equilibrium

Note: The policy parameters $\alpha_{y}$ and $\alpha_{R}$ are set to zero. All structural parameters take their baseline values, given in table 1 .

$\left(\alpha_{\pi}\right.$ and $\alpha_{W}$ ) in the interest-rate rule (48) for which the equilibrium is locally determinate. In producing the figure, the remaining two policy parameters, $\alpha_{y}$ and $\alpha_{R}$, associated with output growth and the lagged interest rate are set to zero. It is clear from the figure that to a first approximation a condition for determinacy is that the sum of the price- and wageinflation coefficients be greater than unity. That is, local determinacy of equilibrium requires that

$$
\alpha_{\pi}+\alpha_{W}>1
$$

The result that the inflation coefficient must be greater than unity for the equilibrium to be unique is easily established in small models with few frictions (see, for example, Leeper, 1991). It is of interest that the same principle applies to a much richer theoretical structure like the one studied in the present paper. Also noteworthy is the apparent perfect substitutability on the margin between the price- and wage-inflation coefficients in ensuring local uniqueness. In effect, at the southwest frontier of the uniqueness area the price- and wage-inflation coefficients satisfy $\alpha_{\pi}+\alpha_{W} \approx 1$.

Local uniqueness of equilibrium is related to the long-run values of the inflation coefficients of the interest-rate rule. In the example discussed thus far, the inertial term of the policy rule, $\alpha_{R}$, is assumed to be nil. As a result, the short- and long-run values of the priceand wage-inflation coefficients coincide and are equals to $\alpha_{\pi}$ and $\alpha_{W}$, respectively. Increasing 
the value of $\alpha_{R}$ to its optimal level of 0.4 results in a local-determinacy area defined by the relation $\alpha_{\pi}+\alpha_{W}>0.4$. This result appears to generalize to other values of the interest-rate coefficient. Thus, the pattern that appears to emerge implies roughly a determinacy area defined by the relation $\left[\alpha_{\pi}+\alpha_{W}\right] /\left(1-\alpha_{R}\right)>1$. In words, the long-run value of the priceand wage-inflation coefficients of the interest-rate rule must add up to a number larger than unity for the equilibrium to be locally unique.

\section{Discussion and Conclusion}

The central focus of the present study is the characterization and implementation of optimal monetary policy in the context of a rich model of the macroeconomy with parameters and sources of uncertainty estimated to fit observed fluctuations at business-cycle frequency.

The central recommendation that emerges from the solution of the Ramses optimization problem is that the central bank should aim at a low and highly stable rate of inflation. This prescription is very much in line with those proposed by advocates of inflation targeting.

At a deeper level, however, the inflation predictions of the Ramsey equilibrium are neither robust nor coincidental with the inflation targeting principles. With respect to robustness, the Ramsey-optimal inflation target varies enormously with the parameter determining the degree of price stickiness. For empirically plausible values of this parameter, the optimal inflation target ranges from the Friedman rule (i.e., minus the real interest rate) to price stability. This apparent hypersensitivity of the optimal rate of inflation calls for an increased effort aimed at obtaining tighter estimates of the amount of nominal sluggishness present in the economy.

An important difference between the predictions of the Ramsey equilibrium studied in the present paper and the observed behavior of central banks adhering to inflation targeting regimes is that the Ramsey optimal rate of inflation is negative (although possibly close to zero) whereas inflation targeters around the world set targets for the inflation rate that are significantly above zero. We establish that in the context of the estimated medium-scale model studied in this paper fear of confronting the zero-bound on nominal interest rates can hardly represent an impediment to adopting the Ramsey-optimal rate of inflation. In effect, in the Ramsey equilibrium the nominal interest rate takes an average value of about 4.5 percent per year, with a standard deviation of about half a percent. It follows that the chances that a shock would push the nominal interest rate to zero are negligible. This result poses the challenge for future researchers of finding a theoretical explanation for the optimality of positive inflation targets. Some have argued that the presence of downward inflexibility in nominal prices and wages may provide a justification for setting positive 
inflation targets. Formalizations of this idea have been limited to highly stylized models. It remains to be seen whether medium-scale models incorporating a realistic degree of nominal downward rigidities can generate optimal inflation targets similar in magnitude to those observed across inflation targeting countries.

The issue of the interaction between optimal fiscal and monetary policy in the context of medium-scale models was touched upon in this paper but requires much further research. We find that the hypersensitivity of the optimal inflation target to the degree of price stickiness alluded to above may disappear under certain fiscal arrangements. This is the case, for instance, when fiscal policy is also set optimally and the fiscal authority has access only to distortionary income taxes. But under alternative fiscal scenarios the hypersensitivity problem may be exacerbated. This is the case, for instance, when the fiscal authority has access to a combination of distortionary and nondistortionary taxes, but distortionary taxes are fixed (even if at the level prescribed by the Ramsey steady state) so that lump-sum taxes are used on the margin to achieve intertemporal solvency.

In this paper we limit attention to an economy driven by three shocks that have been shown to account for a sizable fraction of business cycles in the U.S. economy; namely, neutral and investment-specific productivity shocks and government spending shocks. Ideally, the study of optimal monetary policy would incorporate into the model all of the sources of uncertainty that are important drivers of business cycles in the real world. The current study is admittedly far from this theoretical desideratum. Progress in this area is in order. There is no clear guideline on how to go about in this endeavor. We are skeptical of the approach - recently adopted in some studies - of using the estimation residuals obtained from econometric estimations of the DGE model as structural economic sources of uncertainty. In many instances, these estimation errors are hardly interpretable as structural economic shocks and are more likely a reflection of the fact that theory lags behind business cycles. The dimension of the challenge that the presence of these 'nonstructural' errors pose for macroeconomic theory is demonstrated by the fact that in most of the available estimates of relatively large macroeconomic models, this class of shocks explain the majority of observed business-cycle fluctuations. 


\section{Appendix: Deriving the Welfare Costs Measure}

Consider the Ramsey policy, denoted by $r$, and an alternative policy regime, denoted by $a$. We define the welfare associated with the time-invariant equilibrium implied by the Ramsey policy conditional on a particular state of the economy in period 0 as

$$
\tilde{V}_{0}^{r}=E_{0} \sum_{t=0}^{\infty} \beta^{t} U\left(c_{t}^{r}-b c_{t-1}^{r}, h_{t}^{r}\right)
$$

where $c_{t}^{r}$ and $h_{t}^{r}$ denote the contingent plans for consumption and hours under the Ramsey policy. Using the particular functional form for the period utility function given in equation (46) and setting $\phi_{3}$ to its baseline value of one, we can express the above expression in terms of the stationary transformation of consumption, $C_{t}^{r}$,

$$
\tilde{V}_{0}^{r}=E_{0} \sum_{t=0}^{\infty} \beta^{t}\left(1-\phi_{4}\right) \ln z_{t}^{*}+E_{0} \sum_{t=0}^{\infty} \beta^{t} U\left(C_{t}^{r}-b C_{t-1}^{r} / \mu_{z^{*}, t}, h_{t}^{r}\right) .
$$

Similarly, define the conditional welfare associated with policy regime $a$ as

$$
\tilde{V}_{0}^{a}=E_{0} \sum_{t=0}^{\infty} \beta^{t} U\left(c_{t}^{a}-b c_{t-1}^{r}, h_{t}^{a}\right),
$$

which can be written in terms of the stationary transformation of consumption as follows

$$
E_{0} \sum_{t=0}^{\infty} \beta^{t}\left(1-\phi_{4}\right) \ln z_{t}^{*}+E_{0} \sum_{t=0}^{\infty} \beta^{t} U\left(C_{t}^{a}-b C_{t-1}^{a} / \mu_{z^{*}, t}, h_{t}^{a}\right) .
$$

Let $V_{0}^{r} \equiv E_{0} \sum_{t=0}^{\infty} \beta^{t} U\left(C_{t}^{r}-b C_{t-1}^{r} / \mu_{z^{*}, t}, h_{t}^{r}\right)$ so that

$$
\tilde{V}_{0}^{r}=E_{0} \sum_{t=0}^{\infty} \beta^{t}\left(1-\phi_{4}\right) \ln z_{t}^{*}+V_{0}^{r}
$$

and let $V_{0}^{a} \equiv E_{0} \sum_{t=0}^{\infty} \beta^{t} U\left(C_{t}^{a}-b C_{t-1}^{a} / \mu_{z^{*}, t}, h_{t}^{a}\right)$ so that

$$
\tilde{V}_{0}^{a}=E_{0} \sum_{t=0}^{\infty} \beta^{t}\left(1-\phi_{4}\right) \ln z_{t}^{*}+V_{0}^{a}
$$

Let $\lambda^{c}$ denote the welfare cost of adopting policy regime $a$ instead of the Ramsey policy conditional on a particular state in period zero. We define $\lambda^{c}$ as the fraction of regime $r$ 's consumption process that a household would be willing to give up to be as well off under 
regime $a$ as under regime $r$. It follows that $\lambda^{c}$ is implicitly defined by

$$
\tilde{V}_{0}^{a}=E_{0} \sum_{t=0}^{\infty} \beta^{t} U\left(\left(1-\lambda^{c}\right)\left(c_{t}^{r}-b c_{t-1}^{r}\right), h_{t}^{r}\right) .
$$

Using the definitions given above, this expression can be written as

$$
V_{0}^{a}=V_{0}^{r}+\frac{\left(1-\phi_{4}\right)}{(1-\beta)} \ln \left(1-\lambda^{c}\right)
$$

We restrict attention to an approximation of $\lambda^{c}$ that is accurate up to second order. In equilibrium, $V_{0}^{a}$ and $V_{0}^{r}$ are functions of the initial state vector $x_{0}$ and the parameter $\sigma_{\epsilon}$ scaling the standard deviation of the exogenous shocks (see Schmitt-Grohé and Uribe, 2004c). Therefore, we can write $V_{0}^{a}=V^{a c}\left(x_{0}, \sigma_{\epsilon}\right)$ and $V_{0}^{r}=V^{r c}\left(x_{0}, \sigma_{\epsilon}\right)$. This implies that $\lambda^{c}$ must be a function of $x_{0}$ and $\sigma_{\epsilon}$ as well

$$
\lambda^{c}=\Lambda^{c}\left(x_{0}, \sigma_{\epsilon}\right)
$$

Consider a second-order approximation of the function $\Lambda^{c}$ around the point $x_{0}=x$ and $\sigma_{\epsilon}=0$, where $x$ denotes the deterministic Ramsey steady state of the state vector. Because we wish to characterize welfare conditional upon the initial state being the deterministic Ramsey steady state, in performing the second-order expansion of $\Lambda^{c}$ only its first and second derivatives with respect to $\sigma_{\epsilon}$ have to be considered. Formally, we have

$$
\lambda^{c} \approx \Lambda^{c}(x, 0)+\Lambda_{\sigma_{\epsilon}}^{c}(x, 0) \sigma_{\epsilon}+\frac{\Lambda_{\sigma_{\epsilon} \sigma_{\epsilon}}^{c}(x, 0)}{2} \sigma_{\epsilon}^{2}
$$

Because the deterministic steady-state level of welfare is the same across all monetary policies belonging to the class defined in equation (48), it follows that $\lambda^{c}$ vanishes at the point $\left(x_{0}, \sigma_{\epsilon}\right)=(x, 0)$. Formally,

$$
\Lambda^{c}(x, 0)=0 .
$$

Totally differentiating equation (49) with respect to $\sigma_{\epsilon}$, evaluating the result at $\left(x_{0}, \sigma_{\epsilon}\right)=$ $(x, 0)$, and using the result derived in Schmitt-Grohé and Uribe (2004c) that the first derivatives of the policy functions with respect to $\sigma_{\epsilon}$ evaluated at $\left(x_{0}, \sigma_{\epsilon}\right)=(x, 0)$ are nil $\left(V_{\sigma_{\epsilon}}^{a c}=V_{\sigma_{\epsilon}}^{r c}=0\right)$, it follows immediately that

$$
\Lambda_{\sigma_{\epsilon}}^{c}(x, 0)=0 .
$$

Now totally differentiating (49) twice with respect to $\sigma_{\epsilon}$, and evaluating the result at 
$\left(x_{0}, \sigma_{\epsilon}\right)=(x, 0)$ yields

$$
\Lambda_{\sigma_{\epsilon} \sigma_{\epsilon}}^{c}(x, 0)=\left(\frac{1-\beta}{1-\phi_{4}}\right)\left[V_{\sigma_{\epsilon} \sigma_{\epsilon}}^{r c}(x, 0)-V_{\sigma_{\epsilon} \sigma_{\epsilon}}^{a c}(x, 0)\right] .
$$

Thus, the conditional welfare cost measure is given by

$$
\lambda^{c} \approx\left(\frac{1-\beta}{1-\phi_{4}}\right)\left[V_{\sigma_{\epsilon} \sigma_{\epsilon}}^{r c}(x, 0)-V_{\sigma_{\epsilon} \sigma_{\epsilon}}^{a c}(x, 0)\right] \frac{\sigma_{\epsilon}^{2}}{2} .
$$




\section{References}

Altig, David, Lawrence J. Christiano, Martin Eichenbaum, and Jesper Lindé, "Firm-Specific Capital, Nominal Rigidities, and the Business Cycle," NBER Working Paper No. 11034, January 2005.

Benigno, Pierpaolo, and Michael Woodford, "Optimal Taxation in an RBC Model: A Linear-Quadratic Approach," NBER working paper No. 11029, January 2005.

Bils, Mark and Peter Klenow, "Some Evidence on the Importance of Sticky Prices," Journal of Political Economy 112, 2004, 947-985.

Calvo, Guillermo A., "Staggered prices in a utility-maximizing framework," Journal of Monetary Economics 12, 1983, 383-98.

Carlstrom Charles T. and Timothy S. Fuerst, "Investment and Interest Rate Policy: a Discrete Time Analysis," Journal of Economic Theory, 123, 2005, 4-20.

Chari, V. V., Lawrence J. Christiano, and Patrick J. Kehoe, "Policy Analysis in Business Cycle Models," in Thomas F. Cooley, Frontiers of Business Cycle Research, Princeton, Princeton University Press, 1995.

Christiano, Lawrence J., Martin Eichenbaum, and Charles L. Evans, "Nominal Rigidities and the Dynamic Effects of a Shock to Monetary Policy," Journal of Political Economy 113, February 2005, 1-45.

Cogley, Timothy, and Argia M. Sbordone, "A Search for a Structural Phillips Curve," Federal Reserve Bank of New York Staff Report No. 203, March 2005.

Del Negro, Marco, Frank Schorfheide, Frank Smets, and Raf Wouters, "On the Fit and Forecasting performance of New-Keynesian Models," manuscript, University of Pennsylvania, November 2004.

Erceg, Christopher J., Henderson, Dale W., and Levin, Andrew T., "Optimal Monetary Policy With Staggered Wage and Price Contracts," Journal of Monetary Economics 46, October 2000, 281-313.

Fisher, Jonas D. M., "The Dynamic Effects of Neutral and Investment-Specific Technology Shocks," manuscript, Federal Reserve Bank of Chicago, May 2005.

Galí, Jordi, "Technology, Employment, and the Business Cycle: Do Technology Shocks Explain Aggregate Fluctuations?," American Economic Review 89, March 1999, 249271.

Golosov, Mikhail and Robert E. Lucas, "Menu Costs and Phillips Curves," NBER Working Paper No. 10187, December 2003.

Khan, Aubhik, Robert G. King, and Alexander Wolman, "Optimal Monetary Policy," Review of Economic Studies 70, October 2003, 825-860. 
Kollmann, Robert, "Welfare Maximizing Fiscal and Monetary Policy Rules," mimeo, University of Bonn, March 2003.

Leeper, Eric M., "Equilibria under 'Active' and 'Passive' Monetary and Fiscal Policies," Journal of Monetary Economics 27, February 1991, 129-47.

Levin, Andrew T., Alexei Onatski, John C. Williams, and Noah Williams, "Monetary Policy Under Uncertainty in Micro-Founded Macroeconometric Models," manuscript prepared for the NBER's Twentieth Annual Conference on Macroeconomics, March 31, 2005.

Ravn, Morten, "Labor Market Matching, Labor Market Participation and Aggregate Business Cycles: Theory and Structural Evidence for the United States," manuscript, European University Institute, October 2005.

Rotemberg, Julio J. and Woodford, Michael D., "Oligopolistic Pricing and the Effects of Aggregate Demand on Economic Activity," Journal of Political Economy 100, December 1992, 1153-1207.

Rotemberg, Julio J., and Michael Woodford, "An Optimization-Based Econometric Framework for the Evaluation of Monetary Policy," in Bernanke, Ben S. and Julio J. Rotemberg, eds., NBER macroeconomics annual 1997, Cambridge and London: MIT Press, 1997, 297-346.

Schmitt-Grohé, Stephanie and Martín Uribe, "Optimal Fiscal and Monetary Policy under Sticky Prices," Journal of Economic Theory 114, February 2004(a), 198-230.

Schmitt-Grohé, Stephanie and Martín Uribe, "Optimal Fiscal and Monetary Policy under Imperfect Competition," Journal of Macroeconomics 26, June 2004(b), 183-209.

Schmitt-Grohé, Stephanie and Martín Uribe, "Solving Dynamic General Equilibrium Models Using a Second-Order Approximation to the Policy Function," Journal of Economic Dynamics and Control 28, January 2004c, 755-775.

Schmitt-Grohé, Stephanie and Martín Uribe, "Optimal Simple and Implementable Monetary and Fiscal Rules," Journal of Monetary Economics, 2006, forthcoming.

Schmitt-Grohé, Stephanie and Martín Uribe, "Optimal Operational Interest-Rate Rules in the Christiano-Eichenbaum-Evans Model of the U.S. Business Cycle," Duke University, August 2004d.

Schmitt-Grohé, Stephanie and Martín Uribe, "Optimal Fiscal and Monetary Policy in a Medium-Scale Macroeconomic Model," in Gertler, Mark and Kenneth Rogoff, eds., NBER Macroeconomics Annual 2005, Cambridge and London: MIT Press, 2005(a) forthcoming.

Schmitt-Grohé, Stephanie and Martín Uribe, "Optimal Inflation Stabilization in a MediumScale Macroeconomic Model: Technical Appendix," manuscript, Duke University, 2005(b). 
Smets, Frank and Raf Wouters, "Shocks and Frictions in US Business Cycles: A Bayesian DSGE Approach," manuscript, European Central Bank, April 21, 2004.

Summers, Lawrence, "How should long-term monetary policy be determined?," Journal of Money, Credit and Banking, 23, August 1991, 625-631.

Sveen, Tommy and Lutz Weinke, "Inflation and Output Dynamics with Firm-Owned Capital," mimeo, Universitat Pompeu Fabra, 2003.

Taylor, John B., "Discretion versus Policy Rules in Practice," Carnegie Rochester Conference Series on Public Policy 39, December 1993, 195-214.

Woodford, Michael D., Interest and Prices, Princeton University Press: Princeton, New Jersey, 2003.

Yun, Tack, "Nominal price rigidity, money supply endogeneity, and business cycles," Journal of Monetary Economics 37, 1996, 345-370. 